\title{
WestVirginiaUniversity
}

THE RESEARCH REPOSITORY @ WVU

Graduate Theses, Dissertations, and Problem Reports

2020

\section{Disquiet Depictions}

Olivia L. Oddo

olo0001@mix.wvu.edu

Follow this and additional works at: https://researchrepository.wvu.edu/etd

Part of the Painting Commons

\section{Recommended Citation}

Oddo, Olivia L., "Disquiet Depictions" (2020). Graduate Theses, Dissertations, and Problem Reports. 7507. https://researchrepository.wvu.edu/etd/7507

This Thesis is protected by copyright and/or related rights. It has been brought to you by the The Research Repository @ WVU with permission from the rights-holder(s). You are free to use this Thesis in any way that is permitted by the copyright and related rights legislation that applies to your use. For other uses you must obtain permission from the rights-holder(s) directly, unless additional rights are indicated by a Creative Commons license in the record and/ or on the work itself. This Thesis has been accepted for inclusion in WVU Graduate Theses, Dissertations, and Problem Reports collection by an authorized administrator of The Research Repository @ WVU. For more information, please contact researchrepository@mail.wvu.edu. 


\title{
Disquiet Depictions
}

\author{
Olivia Oddo
}

\author{
Thesis submitted \\ to the College of Creative Arts \\ at West Virginia University \\ in partial fulfillment of the requirements for the degree of \\ Master of Fine Arts in Painting
}

\author{
Naijun Zhang, M.F.A., Committee Chair \\ Hannah Freeman, M.F.A. \\ Eve Faulkes, M.F.A. \\ Dylan Collins, M.F.A.
}

School of Art and Design

Morgantown, West Virginia 2020

Keywords: Painting, Acrylic Painting, Mental Health, Anxiety, Art Therapy, Abstraction

Copyright 2020 Olivia Oddo 


\section{Abstract \\ Disquiet Depictions}

\section{Olivia Oddo}

This written document is the accompanying thesis for my Master of Fine Arts exhibition - Disquiet Depictions. Presented within the exhibition was a collection of paintings, ranging from acrylic to mixed media. As someone living with both anxiety and panic disorder the symptoms that I have experienced, as well as the coping mechanisms that I have practiced, all influenced the paintings displayed within this exhibition. Imagery included self-portraiture across a variety of emotional expressions felt during moments of sporadic fear and happiness, vibrant geometric patterns serving therapeutic purposes, and subtle medication symbolism. Collectively, these paintings provide a visual journey into the realm of mental health by creating a chronicle of the internal and external disturbances experienced by an individual, only to be alleviated by the act of artmaking. Through observing these works the audience can begin to consider how academic art and therapeutic art co-function in order to convey a personal message across all environments that harbor creative expression, therefore extinguishing the stigma that may come from the public display of distress; if compassion or rejection is projected at the individual on a basis of normality, and if their coping mechanism valid. 


\section{Acknowledgements}

At this point of my graduate career here at West Virginia University, I would like to express my gratitude to my committee for their never-ending support, enthusiasm, and insight over the past three years. Working through bountiful ideas with Naijun Zhang during painting courses, as well as his general advising, encouraged me to flourish as a contemporary artist. After discovering the Visual Art Therapy Certification program, I was given the pleasure of taking several courses taught by Anne McFarland, MS, ATR-BC, who provided me with an abundance of support and knowledge concerning the healing properties of art. I would also like to expand my appreciation to those beyond the WVU campus; to Mary Pillow, LCSW for her continuous care, compassion, and support for the visual arts. To my mother, Robin, thank you for raising me to love and care for others, for supporting my art from the first kindergarten doodle, and for being my biggest advocate; and to my undergraduate painting professor, Patrick Schmidt of Washington \& Jefferson College, for igniting the flame in my life that is painting, and for all of the opportunities, the recommendation for WVU, and your continuous support.

While I dedicate this thesis exhibition to all of those previously mentioned, I also dedicate it to every person who survives mental illness on a daily basis with the will to live the fullest life. I dedicate it to every person who is afraid of rejection because of their disorder(s), and to those who simply wish to learn more. 


\section{Table of Contents}

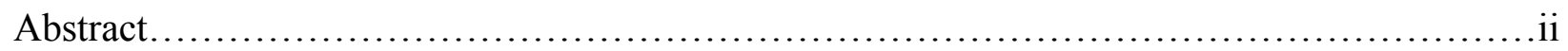

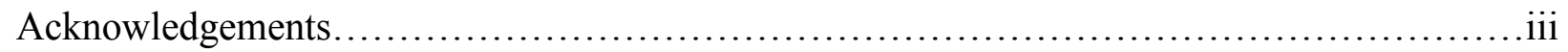

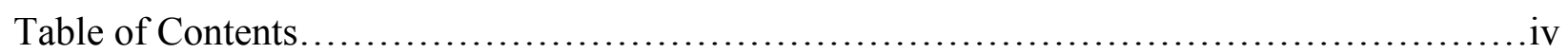

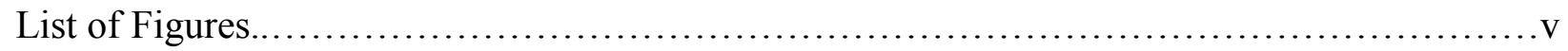

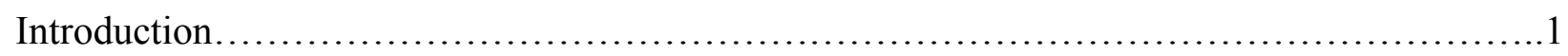

I. Art Influences..................................................................

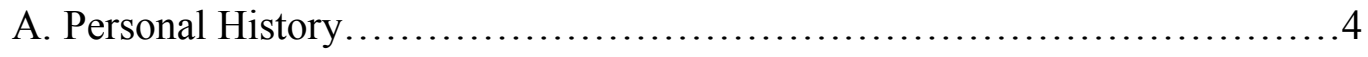

B. Contemporary Painters and Painting History...........................6

II. Disquiet Depictions: Concepts............................................. 13

A. Existence Through Abstraction and Flatness...............................13

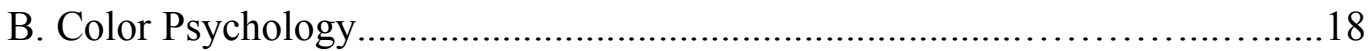

C. Therapeutic Art and Fine Art Coexisting......................................22

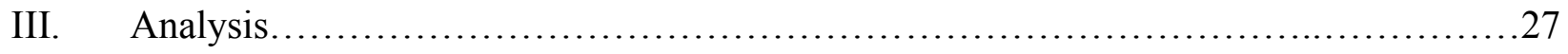

A. Formal Investigation of Paintings..........................................27

B. Conclusion.................................................... 32

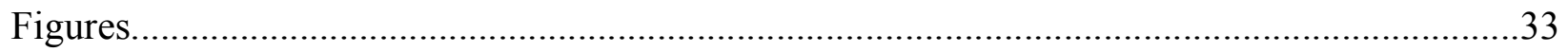

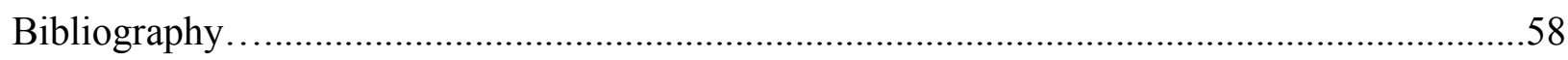

Resumé.....................................................................60 


\section{List of Figures}

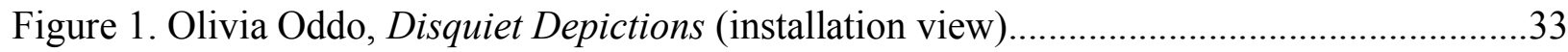

Figure 2. Olivia Oddo, Disquiet Depictions (installation view)............................................33

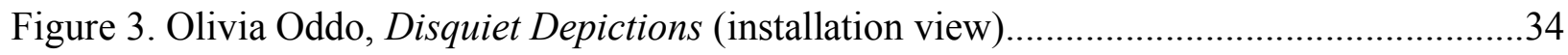

Figure 4. Olivia Oddo, Disquiet Depictions (installation view)..............................................34

Figure 5. Olivia Oddo, Disquiet Depictions (installation view).............................................35

Figure 6. Olivia Oddo, Disquiet Depictions (installation view).............................................35

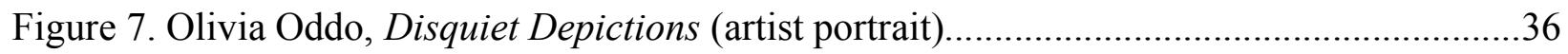

Figure 8. Olivia Oddo, Disquiet Depictions (artist portrait)...................................................36

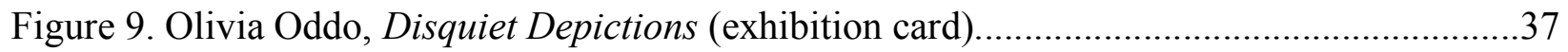

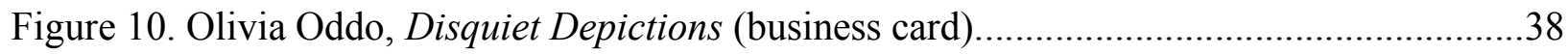

Figure 11. Olivia Oddo, Daily Dose series, acrylic/photograph/tape on canvas, 5x7”, 2019......39

Figure 12. Olivia Oddo, The Dark Side, acrylic/tape on canvas, 24x36", 2020.......................40

Figure 13. Olivia Oddo, Just Take It, acrylic/photograph/tape on canvas, 24x36”, 2019...........40

Figure 14. Olivia Oddo, Don't Panic, acrylic/photograph/tape on canvas, 24x36”, 2019...........41

Figure 15. Olivia Oddo, Like Flipping a Coin, acrylic/photograph/tape on canvas, 24x48”, 2019

Figure 16. Olivia Oddo, You Tell Me, acrylic/tape on canvas, 24x36", 2019..........................42

Figure 17. Olivia Oddo, I'm Listening, acrylic/tape on canvas, 24x36", 2019........................42

Figure 18. Olivia Oddo, These Will Help 1, acrylic/tape on canvas, 24x36", 2020..................43

Figure 19. Olivia Oddo, Do You Feel It?, acrylic/tape on canvas, 48x60”, 2020.....................43

Figure 20. Olivia Oddo, These Will Help 2, acrylic/tape on canvas, 24x36”, 2020...................44

Figure 21. Olivia Oddo, These Will Help 3, acrylic/tape on canvas, 24x36”, 2020..................44

Figure 22. Olivia Oddo, Just Let It Out, acrylic/tape on canvas, 48x60”, 2020........................45

Figure 23. Olivia Oddo, These Will Help 4, acrylic/tape on canvas, 24x36”, 2020.................45

Figure 24. Olivia Oddo, It's Noticeable, acrylic/tape on canvas, 12x24", 2020.......................46

Figure 25. Olivia Oddo, Winding Down, acrylic/tape on canvas, 12x24", 2020....................46

Figure 26. Olivia Oddo, Too Many, acrylic/tape on canvas, 12x24”, 2020............................47

Figure 27. Olivia Oddo, Pacing Helps, acrylic/tape on canvas, 12x24”, 2020.......................47 
Figure 28. Olivia Oddo, Picking on Me series, acrylic/tape on canvas, 5x7”, 2020_................48

Figure 29. Olivia Oddo, Picking on Me series, acrylic/tape on canvas, 5x7”, 2020.................49

Figure 30. Olivia Oddo, Picking on Me series, acrylic/tape on canvas, 5x7”, 2020..................50

Figure 31. Olivia Oddo, You Need to Stop, acrylic/tape on canvas, 48x60”, 2020....................50

Figure 32. Pablo Picasso, Weeping Woman, oil on canvas, 23.6x19.2”, 1937...........................51

Figure 33. Pablo Picasso, Seated Woman, oil on canvas, 23.6x19.2", 1930.............................51

Figure 34. Lyubov' Popova, Untitled Composition, oil on canvas, 19.2x15.5”, 1916.................52

Figure 35. Shannon Finley, torrent 01-19, acrylic on canvas, 31.4x55”, 2019.......................52

Figure 36. Stefaan De Croock, This was so bloody obvious, acrylic/spray paint/markers on

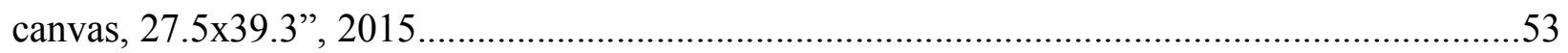

Figure 37. Sarah Wearn, An anxious mind, digital photograph, 2018.......................................53

Figure 38. Douglas Gordon, Trigger Finger, video installation, 1995....................................54

Figure 39. Rae Heller, How We Speak To Each Other, acrylic on canvas, 36x72”, 2020...........54

Figure 40. Wassily Kandinsky, Composition VIII, oil on canvas, 55x79”, 1923.......................55

Figure 41. Wassily Kandinsky, Black and Violet, oil on canvas, 30.6x39.5”, 1923..................55

Figure 42. Mark Rothko, No. 3/No.13, oil on canvas, 85.2x64.8”, 1949................................56

Figure 43. Mark Rothko, Untitled, synthetic polymer paint on canvas, 77.9x66", 1969-1970....56

Figure 44. Lorser Feitelson, Geomorphic Metaphor, oil on canvas, 58x82”, 1950-51.............57 


\section{Introduction}

Disquiet Depictions is a collection of selective works derived from my West Virginia University graduate portfolio, particularly the paintings created from the fourth semester onward. While this show expresses my growth as an artist concerning craftsmanship and stylistic choices, the overall subject becomes increasingly fragmented. These paintings, including the mixed media pieces, provide a visual journey into the realm of mental health by creating a chronicle of the internal and external disturbances experienced by an individual, only to be alleviated by the act of artmaking. Overall, each piece expresses a form of vulnerability depicted through the use of acrylic paint on canvas, as well as artist tape drawings and photographic imagery.

Upon examining my earlier work included within the exhibition, my focus consisted of capturing the fragmented reality of the medication consumption process, from holding the broken pills to swallowing them with water in order to benefit from the post-chemical process. Additional pieces from this period of production include depictions of anxiety prior to taking any medication. These images are riddled with actions of hair pulling, screaming, dilated eyes, pacing feet, plugging ears, and drastic changes in mood. In between these representational photographs are various colored shapes, line patterns, and textural implications that are not only visually stimulating, but also, through color associations suggest variance between the emotions felt within the subject matter through color associations, ranging from calmness, happiness, sadness, anger, and indifference. The repetitive shapes and stimulating colors contrast with the grayscale of anxiety, which represents what is felt during that moment when one's personality disappears from their body due to the fight or flight response. Like blood rushing towards the 
heart and lungs, color leaves the face and extremities, leaving the only traces of expression to reside in how one reacts physically and mentally through their coping mechanisms. In addition to this work I also created two purely abstract pieces one of which references Pablo Picasso's Weeping Woman (1937) (fig.32). With this particular piece I experimented with how the layering of shapes, lines, and colors create an emotionally-driven image. Which is similar to how the formal qualities, such as shape and color, effect the overall emotion evoked from Picasso's painting. During the progressive phases of my work, I began to take the fragmented reality of my own figurative images and the geometric abstraction in a direction that specifically focused on the habits that my disorders evoke. It was also during this time that I began the Visual Art Therapy certification program here at West Virginia University. Because I consider the fragmented shapes to be a representation of consistency and relief in my life, as opposed to the sporadic nature of anxiety and panic disorder, this new program trained me to be even more conscious of the colors and images implemented within each piece to establish greater symbolic significance. I also became more thoughtful as to how I depict my own disorders within each piece. I became specifically concerned with the relatability of each image to another individual who may have the same disorders. I began to create split compositions in order to show how academic and therapeutic art can indeed co-function on a single canvas to show pure tension on one side and then geometric fluidity on the other to induce relief. These paintings I considered to be isolated body narratives that focused on specific parts of myself that mindlessly pick, touch, tap, and rub whenever uneasiness floods my body.

As my work continued to progress beyond these split compositions, I chose to remove the physical divide in order to emphasize that, when combined, academic and therapeutic art create sympathetic and symptomatic works. That the art can be analyzed on a 
critique level concerning craftsmanship and context, as well as internally, as a healing mechanism of self-expression. Therefore, the prior self-portrait transformed into conjoined images of myself echoing across each canvas with subtle positional differences in order to depict the multiplicity of symptoms occurring within a single person, which makes me feel like multiple people. In the background, my geometric coping mechanism continues to exist in the form of solid shapes, as well as tangled, tape line drawings, which function together to create a safety net to hold me within the mapped pathways of darting thoughts. The large orange painting can be read as laughing, cheering, or yelling. The large blue painting can be read as pulsechecking, due to habit or due to anxiety. The large green painting can be read as indifferent or conflicting. In addition to this, each canvas size throughout the show, from the small $5 \times 7$ in pieces to the large $4 \times 5 \mathrm{ft}$ paintings, provides a variety of shapely intimacy and broadness for the viewer. Despite the sizes, the paintings are not intentionally meant to trigger anxiety (however, everyone responds differently), but to instead open the floor as to how self-reflective therapeutic art in a fine art space exists together, is interpreted, and can aid in providing an unspoken voice for those suffering with mental disorders. Needless to say, the considerations that I have made across the evolution of my work influenced my interest in utilizing art as more than just an object that is visually stimulating or appealing: to utilize art as therapy. 


\section{Art Influences}

\section{Personal History}

The root of my interest in art as an academic subject, as well as a therapeutic form of expression, can be traced back to my early adolescence. Drawing materials were always handed over to me by family members as something to occupy myself with, and whenever a picture was completed, I received much praise. The repetitive positive reinforcement continued well into my public-school years as I was dubbed "the quiet girl who could draw anything" by my peers. In high school, I signed up for introduction to art, studio art, advanced studio art, drafting, and graphics - essentially every hands-on class that was offered. Living in the middle of the woods in Southwestern Pennsylvania, I had very little inspiration to go off of that concerned my interest in Pop Art at the time. It was not until my acceptance into Washington \& Jefferson College that I had the opportunity to immerse myself into the colorful world of art.

I was a psychology major with the intention of pursuing art therapy. When it was time for me to declare a major, I made the executive decision to gravitate towards the art department. Upon my entry into a whole new curriculum I began to explore the world of painting; I loved it. My painting professor, Patrick Schmidt, was a geometric abstraction hard-edge painter and supported my contemporary interests to the fullest. I began to look at famous individuals who embraced their mental illness. In a response to their advocacy, I painted bright, Pop Art portraits for my senior show, Limelight. Due to these portraits, I gained recognition across campus and ended up in the college campus newspaper with the headline "Olivia Oddo brings color back to W\&J campus", and the president commissioned me to paint Pop Art versions of the college namesakes for the admission house (which soon turned into long banners on the outside of the 
gym after I graduated). I studied Pop Art in Berlin, Germany as well, traveling to the Bauhaus, Berlin MoMa, and dozens of independent galleries. The experience heavily influenced my interest in the contemporary genre of painting. When I graduated from undergrad, I received the Scholar in Art Award for my work.

Despite my departure from my undergraduate institution my love for painting with acrylics to achieve solidarity and boldness, and the desire to express my experiences with mental illness in order to help others come forward and heal continued well into my graduate studies here at West Virginia University. My focus shifted from famous icons to stigma symbolism, to compulsive repetition, to shattering triangular abstraction, to symptomatic representation through mixed media, then finally to the art therapy-driven echoing self-figure portraits encased by similar, high contrast shapes. The considerations that I have made across the evolution of my work influenced my interest in utilizing art as more than just an object that is visually stimulating or appealing. To me, art does not always have to be tragic or enlightening in order for it to be good work, but by putting one's own personal narrative into the driving background of the overall message creates a whole new purpose for the artist themselves concerning the release of their inner identity, as well as the voice that acknowledges others whenever no one else does this is where the overlap occurs between academic art and therapeutic art. In my opinion, art is meant to be experienced by everyone who harbors the will to look beyond what is readily visible in the ordinary world, to experience that self-reflection. While continuously studying literature that emphasized the recruitment of emotion through figuration, color abstraction, and how the brain compiles all of this information in a process that is purely perceptual, I realized that, to me, this self-reflection also appeared in the form of reductionism in art. 


\section{Art Influences}

\section{Contemporary Painters and Painting History}

During my experiences in graduate studies visiting museums on and off campus, attending visiting artist talks, reading articles, studying in art history courses, and conducting my own independent research, I have found and examined numerous contemporary artists that influence my work. While all of the information has been insightful, my research for Disquiet Depictions spotlights six artists in particular, including Wassily Kandinsky (b.1866 - d.1944, Russian painter), Pablo Picasso (b.1881 - d.1973, Spanish painter), Lyubov Popova (b.1889 d.1924, Russian painter), Lorser Feitelson (b.1898 - d.1978, American painter), Mark Rothko (b.1903 - d.1970, American painter), and Stefaan De Croock (b. 1982, Belgian painter and sculptor). Additional artists may be mentioned merely for comparing my own work stylistically.

Kandinsky predominantly uses form and color to influence the mind to focus its attention on the geometric line work without objectifying the illustrations. His approach has influenced my work, as well as the broader history of abstraction, in which Kandinsky served at the forefront. The Russian painter stated that "form itself, even if completely abstract... has its own inner sound." His expectation within the visual arts was to create a belief that was to be reinforced by the painter's inner strength." ${ }^{2}$ As seen in Composition VIII (1923) (fig.40) the array of expressive colors, the black geometric line drawings, and the composition surpassing the edges of the surface reinforces his idea that vague illusions of reality and a creative mind can surpass what is physically seen in order to observe the sublime messages that elements of design can create by merely existing together in a theoretical and practical way. Within his piece

\footnotetext{
${ }^{1}$ Wassily Kandinsky, Composition VIII (1923), https://www.wassilykandinsky.net/work-50.php.

${ }^{2}$ Wassily Kandinsky, Composition VIII (1923), https://www.wassilykandinsky.net/work-50.php.
} 
Black and Violet (1923) (fig.41) these corresponding forms dominate the space on both physical and emotional levels. Kandinsky believed that his forms came from the back of his mind, where images and ideas connect. ${ }^{3}$ Similar to my own representations of voids, Kandinsky embraced black as part of the composition, in combination with the fields of colored geometry.

Valuing the spiritual aspects of the constructivism concept, Kandinsky stated:

"in great art the spectator does feel a corresponding thrill in himself. Such harmony or even contrast of emotion cannot be superficial or worthless; indeed, the Stimmung of a picture can deepen and purify that of the spectator." $\mathrm{He}$ also stated that "in each picture is a whole lifetime imprisoned, a whole lifetime of fears, doubts, hopes, and joys..." in my paintings, I am working to release this "imprisonment". In terms of color, Kandinsky described how they can appear soft, rough, warm, cold, and even scented, in the sense that they evoke emotional responses within the brain that go beyond the two-dimensional canvas. In addition to his mindful quotes he added that "color is a power which directly influences the soul. Color is the keyboard, the eyes are the hammers, the soul is the piano with many strings. The artist is the hand which plays, touching one key or another, to cause vibrations in the soul." I strive to evoke similar responses through my use of color in my paintings.

In addition to Kandinsky’s constructivism illustrations, Pablo Picasso momentarily advocated for the linearization of realistic figures to basic geometric forms. This cubist essence created fundamental changes in art for those who clung to the third-dimension of a painting surface. Concerning the collective understanding of cubism, Picasso stated during and an interview entitled Picasso Speaks in 1923 for The Arts, New York publication:

\footnotetext{
${ }^{3}$ Wassily Kandinsky, Black and Violet (1923), https://www.wassilykandinsky.net/work-50.php.

${ }^{4}$ Maria Popova, https://www.brainpickings.org/2014/06/02/kandinsky-concerning-the-spiritual-in-art/.

${ }^{5}$ Maria Popova, https://www.brainpickings.org/2014/06/02/kandinsky-concerning-the-spiritual-in-art/.

${ }^{6}$ Maria Popova, https://www.brainpickings.org/2014/06/02/kandinsky-concerning-the-spiritual-in-art/.
} 
... cubism is no different from any other school of painting. The same principles and the same elements are common to all. The fact that for a long time Cubism has not been understood and that even today there are people who cannot see anything in it, means nothing... Cubism is not either a seed or a foetus, but an art dealing primarily with forms, and when a form is realized it is there to live its own life. A mineral substance, having geometric formation, is not made so for transitory purposes, it is to remain what it is and will always have its own form... We give to form and color all their individual significance, as far as we can see it; in our subjects, we keep the joy of discovery, the pleasure of the unexpected; our subject itself must be a source of interest. ${ }^{7}$

Absence of realist detail within a figure encouraged viewers to draw expression and emotion from the formal elements of the paintings, which can be seen in Picasso's Weeping Woman (1937) (fig.32) and Seated Woman (1930) (fig.33). Distortion added to the structure of these paintings, which also emphasized the psychological elements. Color palettes ranged from domestic yellows, browns, and red, to stark white, sickening green, and saddened shades of blue. Aside from the formal elements of design directing the tone of each piece, Picasso's subject matter was always personal, including acquaintances who had witnessed devastation and the anxiety of trying to move beyond those losses. The clear-cut contours of the figures and the underlying metaphors always tended to merge together, creating a synchronized pulsation of tessellated tension. These two specific paintings by Picasso inspired me to create my own renditions concerning how emotion is depicted through a third-party source.

The geometric line work and subliminal color cues were also present in Russian painter Lyubov Popova's work. She expressed interests similar to Kandinsky and Picasso, as to how solid, flat forms can create movement and emotional qualities within a piece of art. In my own paintings, the shapes in which I create are static; due to their tightknit organization, it would appear that movement is not possible. A similar statement could also be made in regards to Popova's work; however, she established a "Statement" to consider how positive and negative

\footnotetext{
${ }^{7}$ Zoya Kocur and Simon Leung, Theory in Contemporary Art Since 1985, Second Edition, 216-17.
} 
attributes of minimalist cubist art can function in order create a visually stimulating piece of work. She claimed that, within painting, the positives include painterly space, which promotes the creation of geometric forms: line as a form of color, color based on its mood and density, energetics concerning the directions in which the lines and hues are traveling, as well as texture concerning the painterly touch or lack thereof. The negative attributes that counteract the positive include the concept of illusionism, whether that be the illusion of a glow or movement amongst forms, literariness, emotions, and recognition. ${ }^{8}$ As seen in Popova's piece Untitled Compositions (1916) (fig.34), she created several intersecting planes of lines and color forming geometric shapes that occupy various hues. Black is included within the palette to create depth and contrasting properties within the composition.

Perceptual depth, emotional color palettes, and a myriad of inspirations were tools that artists, like Lorser Feitelson, utilized to create sleek imagery. Similar to Popova's kinetic energy theory of movement, Feitelson's compositions evolved from formal geometry and solid backgrounds of color. Feitelson stated, "I have tried to create a wonder-world of formidable mood-evoking form, color, space, and movement: a configuration that for me metaphorically expresses the deep disturbance of our time: ominously magnificent and terrifying events, hurtling menacingly from the unforeseeable." entitled Geomorphic Metaphor (1950-51) (fig.44). Two-toned hard edge works such as this expand emotional metaphors concerning the sloping planes of color which guide our thoughts to come up with new meanings, which parallels how I am using plans of color to serve as emotional and psychological metaphors.

Concerning emotional metaphors, Mark Rothko also embraced the simplicity of

\footnotetext{
${ }^{8}$ Charles Harrison \& Paul Wood, Art in Theory 1900-2000, 335.

${ }^{9}$ Lorser Feitelson, https://www.lorserfeitelson.com/new-page.
} 
creating optical effects by using layers of transparent colors to create bold color fields that reveal the intensity of impalpable depth. Rothko stated, 'I'm interested only in expressing basic human emotion, tragedy, ecstasy, doom... If you are moved only by color relationships, then you miss the point." ${ }^{10}$ Within his piece No.3/No.13 (1949) (fig. 42) he explores how to layer transparent color layers on dark, colored ground to create an internal glow through color alone. While there is no direct intent as to what emotions he wishes to evoke with the painting, he encourages chromatic intimacy from the sensations created by viewing such hues in relation to the viewers' own color associations.

Due to my interest in the combination of color and grayscale, another notable Rothko Painting that influences my work is Untitled (1969-70) (fig. 43). This piece does not include any vibrant top colors, or colored ground. The canvas is separated into two portions, consisting of mixed-gray at the bottom, and charcoal-black at the top. The painting exhibited his interest in the Minimalist generation, as well as his distinct emotional fluctuations of emotional being. Rothko stated that "a painting is not a picture of an experience. It is an experience." 11 Referring back to my own work, I also strive for the audience to interpret each of my paintings in a way that mimics free-interpretation, simply because not everyone's experiences in life are the same - it should be no different while viewing a piece of art. According to Nobel Prize winner Eric R. Kandel (b.1929), author of Reductionism in Art and Brain Science (2016), "only by pushing the limits of color, abstraction, and reduction can the artist create an image that liberates us from conventional associations with color and form and allows our brain to form new ideas, associations, and relationships - and new emotional responses to them." ${ }^{2}$ Kandel also compared

\footnotetext{
${ }^{10}$ Mark Rothko, MoMa, https://www.moma.org/collection/works/79687?artist_id=5047\&locale=en\&page=1\&sovreferrer=artist.

${ }^{11}$ Eric R. Kandel., Reductionism in Art and Brain Science, 130.

12 Eric R. Kandel., Reductionism in Art and Brain Science, 126-127.
} 
Rothko's painterly experiments to the practice of biologists who study perception and memory, also known as reductionist science. Kandel commented on how the human eyes and brain process color by stating the following:

... our brain processes different colors as having distinct emotional characteristics, but our reaction to color varies, depending upon the context in which we see them and our mood... Unlike spoken language, which often has an emotional significance regardless of context. As a result, the same color can mean different things to different people and to the same person in different contexts. ${ }^{13}$

For Belgium painter Stefaan de Croock, the variance of visual perception based on personal experiences accompanies the psychological aspect of color. Within pathways of geometric lines lies saturated colors, portraiture, texture, and structural dimension. Croock emphasized that "the melancholic, fragile pose of the figure symbolizes a person... We are all so different and yet so identical." ${ }^{14}$ While his work ranges from contemporary painting to larger than life sculpture, he combines the muted with the vivid, and representation with abstraction, as seen in his piece This was so bloody obvious (2015) (fig. 36). Imagery ranges from himself to other individuals engaging in various activities that create a sense of indifference or anticipation. Croock's work inspired my earlier work including photographic self-imagery, as well as my grayscale use in combination with saturated hues.

Regardless as to how personal the subject of my work is, these historical references as mentioned above have influenced me to embrace free-interpretation within my own artistic practice. The contemporary artists I've studied, such as Kandinsky, Popova, Feitelson, Rothko, and Croock, have proven themselves to be vital to the progression of abstract painting over several decades. While the work of Kandinsky, Picasso, Popova, and Feitelson embraced

\footnotetext{
${ }^{13}$ Eric R. Kandel., Reductionism in Art and Brain Science, 144.

${ }^{14}$ Artist Uses Discarded Doors to Create Giant Street Murals, My Modern Met, June 27, 2015, Accessed March 18, 2020, https://mymodernmet.com/strook-elsewhere-wood-and-paint/.
} 
the emotional energy of line and color within a composition, Rothko focused on the optical effects of color, and Croock concerned with transforming discarded materials and subjects into captivating narratives. However, all of these artists share a passion for symbolism through painting based on personal experiences, as well as relationships. The pieces within my exhibition Disquiet Depictions resemble this devotion, in the sense that I have acquired the skillset to create imagery based on metaphor, symbolism, and narrative in fragmentation. I have also learned to control painting materials in a way that leaves little to no traces of the human hand: a mechanical hardedge style to emphasize opaque emotion. My paintings are continuously influenced by these contemporary painters and their own inspirations as well, from the blank canvas to the colorful surface. 


\section{Disquiet Depictions: Concepts}

\section{Existence Through Abstraction and Flatness}

Upon contemplating the conceptual framework for Disquiet Depictions, I focused on how I felt during moments of vulnerability due to my anxiety disorder. Initially, I began photographing myself in a variety of mindsets and actions that I am known for by loved ones, such as checking my pulse, laughing, crying, or fidgeting with my hands. After documenting the physical representations of my anxiety, I focused on the chronically invisible aspects that no one else has the ability to experience through the general senses: my thoughts, obsessions, and fears. Once I compiled a list of my phobias, I soon realized that expressing my concerns verbally had become ineffective. Therefore, I turned to visual communication through minimalistic metaphor: in other words, abstract painting. In order to exist, physically and mentally, I needed to explicitly expose my atypical life to a world that, in my experience, typically responds indifferently to cognitive health.

Perception of emotion in abstract works is a decoding mechanism that permits viewers to travel beyond the physical surface of art, and into the realm of free-interpretation; which I encouraged to those viewing my exhibition. According to Gilbert J. Rose, M.D. in the Journal of the American Psychoanalytic Association:

... both the psychoanalytic and the aesthetic experiences are conductive to a type of mastery that is characterized by the inner reintegration of feelings with thought and perception.... Both.... tend to overcome various splits....: repressed memories, isolated feelings, denied percepts. Psychoanalysis undoes repression and, largely if not wholly through verbalization, reunites memory and affect. Art counteracts denial and, through sensuous forms, reunites perception with affect. Through different routes, they both make 
affect available again for reintegration with thought and perception [and]... thus tend to restore wholeness. ${ }^{15}$

While viewing abstract art a viewer may experience an appreciation other than what the creator initially intended; the experience may be purely aesthetic concerning the formal elements rather than emotional. Concerning the intellectualization and criticism of this paradox, Rose states:

... viewing a work of art similarly may provide educated guesses as to the psychology of the artist and what the work might have consciously and unconsciously meant to him in terms of expressing and mastering underlying personal conflicts. For example, it has been theorized that the private purpose of Piet Mondrian's art was to safely wall off motion and emotion onto rectangles and that 'he was clearly eradicating the family circle and any of the comforting rounded forms of life and human contact.' 16

The inner structure of a physical form articulates the balance between subjective reality and the expressive narrative of a piece. Cubism permitted painting to embrace this plane of balanced and unbalanced objects with descriptive titles. Direct representations of familiar shapes, such as squares, triangles, and rectangles, are considered to be inherently safe. Skewed or distorted designs of typical building blocks are unsettling and lack a sense of closure. A mixture of these patterns or a consistent rhythm of one in particular across a painting exposes the emotional power of art, in conjunction with highly saturated colors. Abstract art then becomes a "container of emotion" that the public can use as a refuge to theorize the meaning of a painting based on their own experiences and "guesses", without judgement from society, which can create an immediate sense of wholeness. ${ }^{17}$

In addition, Jungian analyst Ann Belford Ulanov describes the connections between self-fragmentation and art within her book, Madness \& Creativity (2013), as an effort to

\footnotetext{
${ }^{15}$ Gilbert J. Rose, M.D. Abstract Art and Emotion: Expressive Form and the Sense of Wholeness. Journal of American Psychoanalytic Association, 39(1) 211-212.

${ }^{16}$ Gilbert J. Rose, M.D. Abstract Art and Emotion: Expressive Form and the Sense of Wholeness. Journal of American Psychoanalytic Association, 39(1) 136.

${ }^{17}$ Gilbert J. Rose, M.D. Abstract Art and Emotion: Expressive Form and the Sense of Wholeness. Journal of American Psychoanalytic Association, 39(1) 152.
} 
"express unbearable pain... catastrophic anxiety... an engulfing fog of abysmal confusion." 18

Essentially, through abstract art we create existence by bridging symbolic meaning and the consciousness of obsessive thoughts. Ulanov calls this "the plight of modern man."19 This plight, or what I prefer to call chaos, is an endless battle that may only be won if acceptance from others is offered to those who are mentally suffering. In relation to Rose's description of an emotional container, Ulanov states:

... we feel madness because we have lost our sense of meaning - that we have meaning, that we can make meaning out of what happens to us, that we share containers of meaning with others in our culture... We live in a time when invisible, basic patterns of orientation that sketch a map, a locale, a surround we hardly named or knew existed now rise into mind because they break up. We grab this shard, that pith of content and try to re-form, reinstitute what was... This collective disorientation goes deeper: we lose not just the container of meaning but also our accustomed ways of thinking and feeling about meaning. ${ }^{20}$

Concerning the personal inventiveness of wholeness through abstraction, Ulanov continues to share this active engagement of creating shapely meaning throughout the remainder of her text.

The American Abstract Artists group, originally founded in 1936, advocated for universality of art and idealized European Abstract Art. According to the group in an editorial statement in 1938:

... abstract, like so many other words, is too often used as an idiosyncratic suggestion, rather than as a concept which defines particular values. To understand abstract art is, in reality, no more a problem than understanding any and all art. And this depends upon the ability of the individual to perceive essentials, to perceive that which is called universally significant, and to evaluate the unity and relationship that is contained in any work. ${ }^{21}$

Concerning the contemporary movements during this period, the group urged for the overall acceptance of the interpretation of all artistic culture. This in itself paved a pathway for the

\footnotetext{
${ }^{18}$ Ann Belford Ulanov, Madness \& Creativity, 8.

${ }^{19}$ Ann Belford Ulanov, Madness \& Creativity, 11.

${ }^{20}$ Ann Belford Ulanov, Madness \& Creativity, 21.

${ }^{21}$ Zoya Kocur and Simon Leung, Theory in Contemporary Art Since 1985, Second Edition, 396.
} 
progression of abstraction to become relevant in studios, galleries, history books, and conceptual existence in the world of visual communication.

Within David Joselit's theoretical publication, Notes on Surface: Toward a

Genealogy of Flatness (2000), he discusses flatness within painting as an enhanced model of perceptual stimulation in the simplest form. Joselit stated:

... the emergence of the flat painting marks a transformation in spectatorship in which mimetic identification with the picture is displaced by the private kinesthetic experience of the viewer. The event, as it were, moves from the conscious to the unconscious. To put it schematically, abstraction functions as a machine for recording the psychological responses of the artist in order to produce (perhaps dramatically different) psychological responses in the viewer... I will argue that flatness may serve as a powerful metaphor for the price we pay in transforming ourselves into images - a compulsory spectacularization which is the necessary condition of entering the public sphere in the world of late capitalism. ${ }^{22}$

Joselit references American essayist Clement Greenberg (b.1909 - d. 1994) during his explanation concerning the equation between technique and emotion. Greenberg was known for explaining the self-contradictory relationship between human expression and painterly technique. According to Joselit:

... Greenberg establishes a chain of equivalences between optical qualities and emotional states: tautness of feeling is opposed to depth, the 'flattening out of convexities and concavities' is linked to what the artist 'can vouch for', which ought to be his authentic emotions - those which have narrowly escaped 'exclusion'. Flatness here is imagined as a density or even an impaction of feeling. Consequently, depth is bifurcated into emotional and optical registers... The expression of psychological depth requires the sublimation of optical depth. ${ }^{23}$

The overall flatness of abstract painting creates an active existence for the artist's symbolic imagery pertaining to their personal experiences, as well as validity for the artwork itself. In a collective chaos of obscure shape, line, and color, the outside world of reality becomes an inner

\footnotetext{
${ }^{22}$ Zoya Kocur and Simon Leung, Theory in Contemporary Art Since 1985, Second Edition, 103.

${ }^{23}$ Zoya Kocur and Simon Leung, Theory in Contemporary Art Since 1985, Second Edition, 105.
} 
dialogue of ambiguity. Visual kinetic energy of geometric patterns liberates the mind to evoke positive, negative, and indifferent associations pertaining to radically simplistic paintings. 


\section{Disquiet Depictions: Concepts}

\section{Color Psychology}

Although my personal experiences drive the imagery within Disquiet Depictions, the biological basis of how the brain perceives color, emotionally responds, and creates direct associations with various hues, was an additional concept that I wished to address. Within the structure of the brain the hippocampus directs the function of memory while the amygdala ignites all emotion. According to Nobel Prize winner Eric R. Kandel, author of Reductionism in Art and Brain Science (2016), Mark Rothko reduced images to color in order to evoke emotional responses. Rothko's paint layering technique, as a reductionist color-field artist, inspired a new appreciation for the emotional elements of design. Kandel stated:

...in focusing on color, Rothko was searching for a new style of abstraction that would link modern art to ancient mythic and transcendent art forms that reach out to the infinite. To achieve this, he abandoned figuration and focused exclusively on the expressive power of large fields of color. His experiments inspired a number of artists to follow his lead, to free color from objective contexts, inhibit access to figurative associations, and make it a subject on its own. ${ }^{24}$

Concerning these elements, Wassily Kandinsky discussed within his publication

Concerning the Spiritual in Art (1982) that the human eye is attracted to the qualities of color.

Kandinsky believed that colors can be experienced in a physical sense concerning temperature,

taste, and smell, etc., and psychologically on an emotional level. Kandinsky stated:

... the psychological power of color becomes apparent, calling forth a vibration from the soul. Its primary, elementary physical power becomes simply the path by which color reaches the soul... Color can thus conjure up the memory of another physical agent... Anyone who has heard of color therapy knows that colored light can have a particular effect upon the entire body. Various attempts to exploit this power of color and apply it to different nervous disorders have again noted that red light has an enlivening and stimulating effect upon the heart, while blue, on the other hand, can lead to temporary

\footnotetext{
${ }^{24}$ Eric R. Kandel., Reductionism in Art and Brain Science, 130.
} 
paralysis... In general, therefore, color is a means of exerting a direct influence upon the soul. $^{25}$

Farber Birren explained in his publication, Color Psychology and Color Therapy (2013), that the influence of color on the human population that continues to fascinate and inspire those interested in the chromatic world around them. Concerning mental disorders, Birren referred to an article from the American Journal of Ophthalmology by James E. Reeder, Jr., which stated that the most miniscule area of sensitivity to color in the eye is for green, then red, then blue, with black and white sensitivity residing within the peripheral areas. Abnormal distribution of this sensitivity over the retina in humans can signify mental dysfunctions. ${ }^{26}$ Concerning the physical effects of color beyond the eye, hue illumination can increase and decrease processes such as blood pressure, blood sugar, hormone distribution, oxygen intake, and muscle responsiveness. Birren stated that:

... warm hues, being aggressive and stimulating, have most potency in brilliant light, while cool hues, more passive and subduing, lend themselves to suppressed light... Unquestionably color does have a physical effect upon the human organism. Brightness and warmth of color stimulate the autonomic nervous system... Conversely, dimness and coolness of color release the stimulation of the autonomic nervous system. ${ }^{27}$

The colors of the spectrum symbolize various psychological associations when analyzed in everyday life, including the visual arts. It should be noted, however, that emotional analogies are based off of individual experiences concerning culture, academics, and imagination; therefore, individual responses may vary. To begin with, the grayscale hues - white, black, and variations of gray itself - imply the absence of stimulation. White symbolizes infinite space, but lacks depth. Gray absorbs the light without intensifying or fading. Black implies a

\footnotetext{
${ }^{25}$ Charles Harrison \& Paul Wood, Art in Theory 1900-2000, 89.

${ }^{26}$ Farber Birren. Color Psychology and Color Therapy, 118-19.

${ }^{27}$ Farber Birren. Color Psychology and Color Therapy, 133.
} 
subjective depth that fills an area: solidarity or a gapping emptiness that appears stronger when illuminated. Birren called this "retinal chaos." ${ }^{28}$ Blue evokes a response of slower elongated breaths, subduing, and sober. Orange relates to being lively, energetic, and exuberant, because it is a mixture of red, which dilates or constricts blood vessels (a soothing or tensing reflex action to the nerves) and stimulates intense hormones, and yellow, a color proven to reduce depression and melancholy, and elevate visual awareness. Green conjures feelings of discouragement, guilt, and ghastliness because it is a color that provides little to short-term relief amongst mental patients. Purple represents a soft atmosphere that is mystic, but may also imply desperation. ${ }^{29}$

Amongst all of the pioneers of color psychology, Edwin D. Babbitt (b.1828 - d.1905) and J. Dodson Hessey (b.1867 - d.1952) contributed to the vivifying movement of "chromopaths." Babbitt concerned himself with the harmonic interactions between color illumination and how it could be applied as a healing mechanism. He is famously known for his publication entitled The Principles of Light and Color (1878). Within this text he states:

... the triangle, like the red color for which it answers, is bold and stimulating and the coarsest of forms, as that is the coarsest of colors. The circle, answering to the blue color, and the type of all curvature, is soothing and fine in its degrees, while the hexagon, like the yellow color, is the medium between extremes... ${ }^{30}$

As a scientist and artist, he had infinitely measured the objective and subjective implications of light and color. Because of Babbitt's contributions Birren stated:

... we shall do well, then, to consider this potential and beautiful principle of light and its component colors, for the more deeply we penetrate into its inner laws, the more will it present itself as a marvelous storehouse of power to vitalize, heal, refine, and delight,

\footnotetext{
${ }^{28}$ Farber Birren. Color Psychology and Color Therapy, 185.

${ }^{29}$ Farber Birren. Color Psychology and Color Therapy, 143.

${ }^{30}$ Edwin D. Babbitt, The Principles of Light and Color, 64.
} 
mankind. Within light and color Babbitt saw unity. He developed an all-encompassing harmonic law and declared: 'Unity exists in absolutely all unimpeded natural growth.' 31 Hessey researched the effects of color pertaining to physical and mental disease, eventually leading to his spectrum gradient theories. Birren pointed out that despite how frequently the American Medical Association views the effects of color skeptically, color will always be a cure of finer elements. Hessey stated within Birren's text that “the great importance of Color lies in the fact that it can influence all the different aspects man - physical, emotional, mental, and spiritual, and so help to produce that harmony which in itself implies perfect health." ${ }^{32}$ Birren reinforced the idea that color could be prescribed, such as Babbitt and Hessey did, and that it's vibrancy established a bridge between physical and emotional healing.

Kurt Goldstein (b.1878 - d.1965), a psychologist studying aspects of color, is referenced by Birren as well concerning the equilibrium effects of vibrancy on a human being. Goldstein stated:

... life is a condition alternating between excitation, destruction, and unbalance, and reorganization, equilibrium, and rest. In the course of life colors play their role. Each color has a special importance and all colors together help to guarantee normal life... It is probably not a false statement if we say that a specific color stimulation is accompanied by a specific response pattern of the entire organism... How color therapy, based on experimental research about the influence of colors on the function of the organism, may be helpful in treatment of neuroses and psychoses the future will reveal. ${ }^{33}$

Common tasks influenced by colors of various saturations and lighting conditions directly influence the nervous system and all bodily functions, from cognition, to balance, to general health.

\footnotetext{
${ }^{31}$ Farber Birren. Color Psychology and Color Therapy, 55.

${ }^{32}$ Farber Birren. Color Psychology and Color Therapy, 59.

${ }^{33}$ Farber Birren. Color Psychology and Color Therapy, 144-46.
} 


\section{Disquiet Depictions: Concepts}

\section{Therapeutic Art and Fine Art Coexisting}

The atypical occurrence of therapeutic art existing in a fine art gallery was also

a consideration for Disquiet Depictions. Although I made the ultimate decision to publicly

display such personal imagery as an artist, if I were an art therapy client, it would have to be

legally approved to do so according to the American Art Therapy Association, Inc. Within the

Ethical Principles for Art Therapists guidelines it states within Section 4.0 Client Artwork:

4.4 Art therapists obtain written informed consent from clients or legal guardians (if applicable) before photographing clients' artwork or video-taping, audio recording, otherwise duplicating, or permitting third party observation of art therapy sessions. ${ }^{34}$

In Section 5.0 Exhibition of Client Artwork, it explains that, while clients may have the

opportunity to publicly show their artwork the benefits must be weighed prior to installing.

Typically, the exhibition of therapeutic work, according to the association "... has the potential

to inform the public and empower the clients, while decreasing stigma and preconceptions." 35

Subsections within this topic include the following:

5.3 In selecting artwork for exhibition, art therapists help clients make decisions based on several factors, including reason(s) for the display of the artwork, the therapeutic value of the artwork to the clients, the degree of self-disclosure, and the ability to tolerate audience reactions.

5.6 Art therapists obtain written informed consent from clients or, when applicable, parents or legal guardians, in order to exhibit client artwork. Art therapists discuss with clients, parents or legal guardians how the exhibition will be described and advertised to

\footnotetext{
${ }^{34}$ American Art Therapy Association, Inc. Client Artwork. Section 4.0.

${ }^{35}$ American Art Therapy Association, Inc. Exhibition of Client Artwork. Section 5.0.
} 
the public and viewing audience to ensure their consent in being associated with the exhibition.

5.8 Art therapists clearly state where and when exhibitions will take place to ensure that clients understand the range of possible audience members and degree of public exposure.

5.9 With regard to on-line exhibitions, art therapists make clients aware of the widespread availability of images, and therefore the enlarged viewing audience, as well as the potential for their images to be downloaded, forwarded or copied by on-line viewers. ${ }^{36}$

While the differences between therapeutic art and fine art are quite clear it is fair to speculate

how the two complement each other, and collectively benefit the creator.

Art therapist Deborah Schroder provided an example within her book Little

Windows into Art Therapy: Small Openings for Beginning Therapists (2005) while visiting one

of her friends who was traumatized. Schroder stated:

... I was a little surprised by her painting. A writhing two-headed snake had appeared on the page, each snake's mouth grinning wildly, eyes eerily glowing. 'It's me, Miss Bipolar Milwaukee!' She looked up with a smirk. 'It's all anyone sees. Anna did you take your meds? Anna did you sleep last night? Anna, your teacher called again.' She seemed to be watching for my reaction... Some of the most powerful healing moments that I have experienced, after witnessing traumatic client work, have been through my own artmaking. The sooner that I can create art as an intentional response to a particular image that I've seen that day. Other times I just start painting and let myself get lost in the physicality of moving the colors around. ${ }^{37}$

Whether one creates art for the sake of reflection, the mastering of craftsmanship, or a combination of both, the imagery has the potential to be viewed by others who may or may not understand. Regardless, art forces the creator to be physically present with their subconscious regardless of the chosen medium.

Natalie Rogers (b.1928 - d.2015), a leader in Expressive Art Therapy and

\footnotetext{
${ }^{36}$ American Art Therapy Association, Inc. Exhibition of Client Artwork. Section 5.0.

${ }^{37}$ Deborah Schroder. Little Windows into Art Therapy: Small Openings for Beginning Therapists, 63-66.
} 
author of The Creative Connection: Expressive Arts as Healing (1993), explains the core connections between experiential training and self-healing. She also stresses humanistic principles such as the universal ability to create, the healing process of creativity, personal growth, and insight into our emotions. Rogers stated:

... expressive arts emphasize the process of self-expression. It is the process rather than the product that heals, informs, and creates avenues for insight and development. Visual arts offer the opportunity to express ourselves dramatically, poignantly, and colorfully, thereby gaining insights as to who we are... Being keenly aware of the inner self helps us connect our inner reality to the outer world, bringing us closer to nature and other humans. It can also foster a global perspective. ${ }^{38}$

Judith A. Rubin (b.1936), an American art therapist and author of Introduction to Art Therapy (2010), provides resources for both artists and art therapists. She stated that:

... art is sensual, enabling you to feel your impact on the physical world, and increasingly rare experience in these technologically sophisticated but humanly impersonal times. And if you look at the world through artist eyes, you can see more loveliness in ordinary things. ${ }^{39}$

This artist eye, applicable in therapeutic art and fine art combined, allows a viewer to decipher nonverbal symbols and metaphors.

Cathy A. Malchiodi, expressive arts therapist in trauma healing, speaker, and author of The Art Therapy Sourcebook (2007), explained the earliest recorded method of communication with rediscovered benefits in conjunction with fine art. She explained that "Art + Therapy $=$ Process + Product" ${ }^{\prime 4}$ is a way of visual thinking; as humans we have a tendency to project our ideas and beliefs onto images we view. Words are not always an adequate way to present true emotions, therefore art (both in a therapeutic and fine art sense) defy the rules of syntax in order to communicate our existence through the elements of design. By making art, for whatever reason it may be, we offer new ways to view ourselves, as well as

\footnotetext{
${ }^{38}$ Natalie Rogers. The Creative Connection: Expressive Arts as Healing, 70-71.

${ }^{39}$ Judith A. Rubin. Introduction to Art Therapy, 275.

${ }^{40}$ Cathy A. Malchiodi. The Art Therapy Sourcebook, 6.
} 
others, through divergent thinking. According to Malchiodi this involves "moving beyond perceived limits; synthesizing and integrating unrelated elements; and reorganizing or altering previously accepted thoughts, ideas, and perceptions." ${ }^{" 41}$ She also acknowledged that the creative process occurs in the following stages for both therapeutic and fine art: ${ }^{42}$

\section{Preparation}

\section{Gathering materials and ideas.}

\section{Incubation}

Becoming absorbed in the process.

\section{Illumination}

Experiencing a breakthrough and achievement.

\section{Verification}

\section{Adding final touches or making changes.}

Overall, therapeutic art in a fine art space, such as a gallery, should pose the following questions: how do these two forms of art successfully coexist together concerning my own interpretation as the viewer? How important is it that this type of personal work be shown outside of a therapist's office? Does the fine art space make the therapeutic art fine art itself if the artist expresses craftsmanship? Audience members overall could exit the gallery with feelings of pleasure,

\footnotetext{
${ }^{41}$ Cathy A. Malchiodi. The Art Therapy Sourcebook, 70.
}

${ }^{42}$ Cathy A. Malchiodi. The Art Therapy Sourcebook, 66. 
uneasiness, and/or further questions concerning the relevance of art as a dual tool concerning fine and therapeutic art practices. 


\section{Analysis}

\section{Formal Investigation of Paintings}

I believe that art does not always have to be tragic or enlightening in order for it to be good work, but by putting one's own personal narrative into the driving background of the overall message creates a whole new purpose for the artist themselves concerning the release of their inner identity, as well as the voice that acknowledges others whenever no one else does which is where the overlap occurs between academic art and therapeutic art. To me, art is meant to be experienced by everyone who harbors the will to look beyond what is readily visible in the ordinary world, to experience that self-reflection. For me, this self-reflection also appeared in the form of reductionism in art upon continuously studying literature that emphasized the recruitment of emotion through figuration, color abstraction, and how the brain compiles all of this information in a process that is purely perceptual. This concept of reductionism through the use of shapes led me to create the paintings within the exhibition.

Upon examining my earlier work included within the exhibition, my focus consisted of capturing the fragmented reality of the medication consumption process; holding the broken pills to swallowing them with water in order to benefit from the post-chemical process as depicted in Daily Dose (2019) (fig. 11). Additional pieces from this period, such as Just Take It (2019) (fig. 13), include depictions of anxiety prior to taking any medication. These images, also seen in Don't Panic (2019) (fig. 14) and Like Flipping A Coin (2019) (fig. 15), are riddled with actions of hair pulling, screaming, dilated eyes, pacing feet, plugging ears, and drastic changes in mood. In between these representational photographs are various colored shapes, line patterns, 
and textural implications that are not only visually stimulating, but also suggest variance between the emotions felt within the subject matter through color associations; ranging from calmness, happiness, sadness, anger, and indifference. The repetitive shapes and stimulating colors contrast with the grayscale of anxiety, representing what is felt during that moment when one's personality disappears from their body due to the fight or flight response. Like blood rushing towards the heart and lungs, color leaves the face and extremities, leaving the only traces of expression in how one reacts physically and mentally concerning their coping mechanisms.

During the progressive phases of my work in comparison to my initial compositional ideas, I began to take the fragmented reality of my own figurative images and the geometric abstraction in a direction that specifically focused on the habits that my disorders evoke. The paintings It's Noticeable (2020) (fig. 24), Winding Down (2020) (fig. 25), Too Many (2020) (fig. 26), and Pacing Helps (2020) (fig. 27), represents mental illnesses that I, as well as possibly others, occupy from day to day life, including OCD, agoraphobia, anxiety, and insomnia. A red triangle can be identified within each painting; interrupting a pattern (the vital routine of $\mathrm{OCD}$ ), receiving a funnel of multiple shapes through the top point (the late-night thoughts of insomnia), balancing a rigid pattern of shapes in a vertical pulse or wave-like manner (the fluidity of anxiety), and feeling surrounded by too many occupants at once (the stage-fright of agoraphobia). The red triangle, and reductionist concept, can also be seen in the larger geometric piece, The Dark Side (2020) (fig. 12), pictured in the vestibule. This piece deals with the concept of my daily life, in particular; with the others, the red triangle represents myself (under pressure - red being a cautious color) within each situation. Here, the red triangle is propping up a split triangle - the array of colors that are my daily emotions and paralleled routines as someone living with such disorders. The darker gray portion is that of my more 
desensitized days, but the outline of my previous life in color still exists (the black tape within the gray, as seen outlining the colored portions). I decided to place this piece at the forefront of my exhibition layout (in the vestibule) because I believed that it represented the overall relationship between color and grayscale - how the two interact and balance within a composition, the therapeutic representation of my own experiences without direct imagery, and the raising introductory questions (after looking at the five smaller pieces in the vestibule of pills and shapes) such as "how does this relate to those?... what does this mean to the artist and what am I drawing connections to concerning myself?”.

Throughout all of my work, the use of tape can be seen. I believe tape has been the most controversial material I decided to implement. The pill paintings, entitled These Will Help (2020) (figs. 18, 20, 21, 23), utilize the tape in a way that implies the supplements are either rolling around trying or trapped in these tangled tape webs of thought, which prevent the pills from dissolving, therefore preventing their purpose. Tape is typically considered a process material; however, I adhere it to the acrylic paintings as a finishing touch, either whether it be to create a drawing of tangled lines, or to imply that the tape is somehow holding the solid shapes together, as a bandage would against a wound. One could say that these shapes even represent emotional wounds. Similar to Popova's positive and negative attributes of minimalist cubist art, the black tape promotes the creation of energetics: line as a form of color, color based on mood and density, and other contrasting properties of a flat surface. Because I used the tape to create the initial shapes during the painting process as a hard-edge painter, and because art therapy focuses on the process rather than the product by implementing the tape as an element, through using tape as a finishing touch in my paintings. I am also referencing back to their original stages of creation. Similar to the process of a progressive memory, disorder, or identity, it all has a starting 
point. Within the larger pieces such as Just Let It Out (2020) (fig. 22), I also used the tape to create line drawings of anxiety webs that bounce off of the orange paint. Acrylic painter Rae Heller implements similar sprawling line work within her symbolic pieces, such as How We Speak To Each Other (2020) (fig. 39). The purpose of the tape behind and on top of the faces was to emphasize that this web in itself is tangled: sometimes there are denser areas to work through strand-by-strand, other times, there are areas that are easier to overcome. Feeling conflicted or like two people at once, not knowing how to feel or what is appropriate to express in public, the figures contradict each other within the grayscale. Mixed media artist Sarah Wearn in her piece An Anxious Mind (2018) (fig. 37) also portrays a tri-split rippling of herself during a moment of sensory overload. This feature has influenced my larger double portraits.

The isolated body narratives, such as entitled Picking on Me (2020) (figs. 28, 29, 30), depicts a nervous habit that I occupy: fidgeting and picking my hands. This cut-reel arrangement of movement includes a variation of the color blue. The darker blue paintings represent moments of toxic stress, and the lighter blue paintings represent moments of tolerable stress. The scale of the series forces the viewers to move forward very closely, which relates to how my family members, catching me in the act, come close to me to grab my hands and examine my fingers for hangnails. Mixed media artist Douglas Gordon created a video installation entitled Trigger Finger (1995) (fig. 38) and captured still-images of his own hand motions as well to emphasize narrative and gesture.

As a contemporary abstract artist who also occupies an interest in art therapy, I'm entirely in favor of free-interpretation of my work. For me, painting is a practice of deliberate manipulation; I consciously make choices concerning colors, lines, shapes, and imagery to best 
satisfy what I'm thinking about or feeling. In comparison, mental illness is not a deliberate form of manipulation, but is instead a biological manipulation of the growing mind. Painting in bold color-specific layers and orders to create opacity, for me, makes the work exclaim its own presence in a gallery setting without objectifying the overall composition; therefore, promoting my brain (as well as hopefully others' brains) to form new ideas, associations, and emotional responses. With the older works setting the mood with direct imagery of distress and selfmedication, the newer works become more about personally coping, depicted through abstract symbolism, continued self-medication, and expressing nervous tendencies. To me, it is a fluctuating narrative that has to be given a conclusion. The definition of the term "disquiet" is a feeling of anxiety or worry, while the definition of the term "depiction" is the action or result of depicting something, especially in art. I believe that this collective exhibition of works, Disquiet Depictions, has permitted me to reflect on my true identity as a healer, educator, and artist. 


\section{Conclusion}

As the vibrant fragmentations and geometric line work span across each picture plane that I have created, the overall goal of my painting practice is to establish wholeness out of the organized chaos that is my mental illness. Deconstructing each image conceptually and figuratively through the process of digital manipulation, I layered each section of paint without leaving a trace of my hand in an effort to emphasize the solidarity of these issues, as well as the compulsive nature of these coping mechanisms. Through the act of moving paint across the canvas in sections, lifting tape to find crisp lines, and explicitly depicting my experiences, I have found my practice to be therapeutic.

By immersing myself within theoretical texts, art history courses, and researching contemporary artists, I was able to further progress as an abstract painter. My newfound knowledge benefited my graduate work and granted me the confidence to also pursue the Visual Art Therapy graduate certificate program here at West Virginia University. Discussing ideas with faculty and fellow students also aided in my personal growth, as well as further influenced my interest in free-interpretation.

My post-graduate practice will include the continuation of expanding my painting portfolio consisting of bold imagery pertaining to mental health. While I will always refer to my prior artistic influences, thoughtfulness as to how I represent these issues will always encompass my work. I happily await to see where the visual arts will guide me to next. 


\section{Figures}

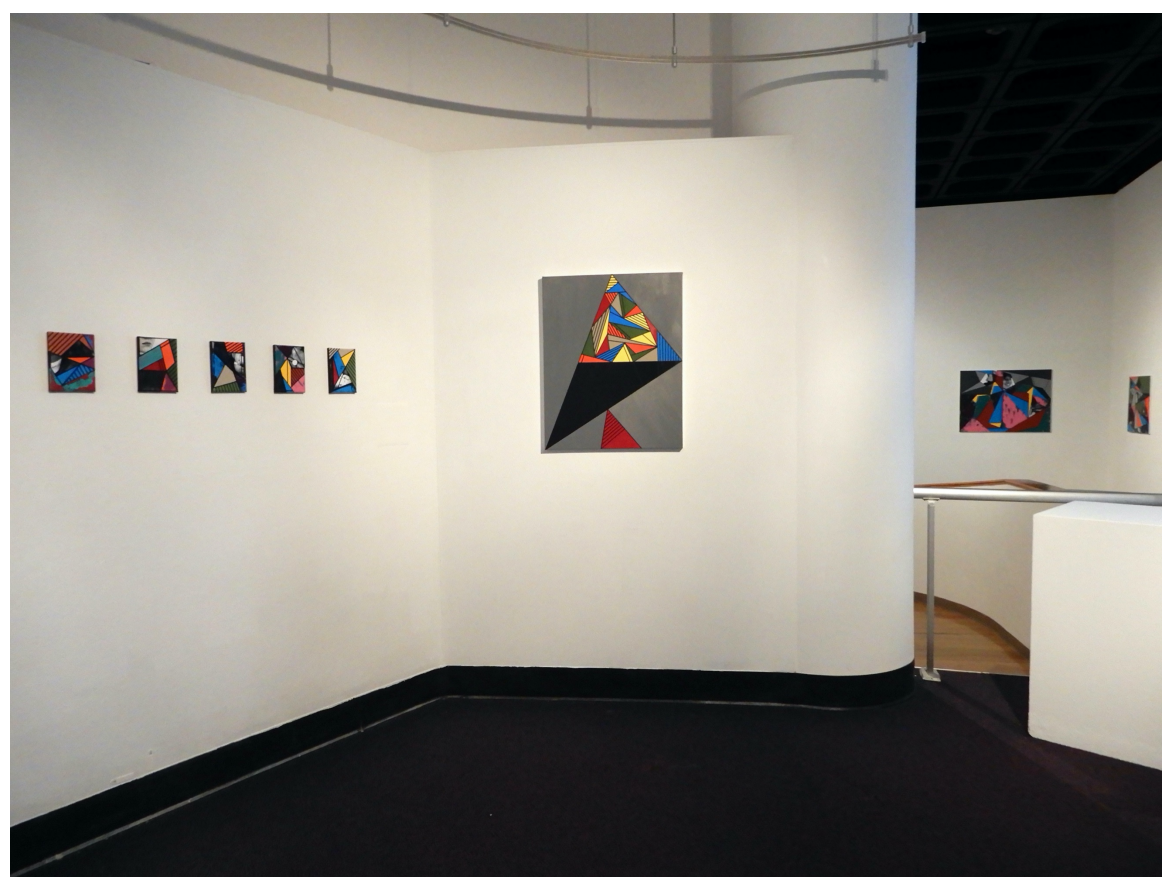

Figure. 1, Olivia Oddo, Disquiet Depictions (installation view).

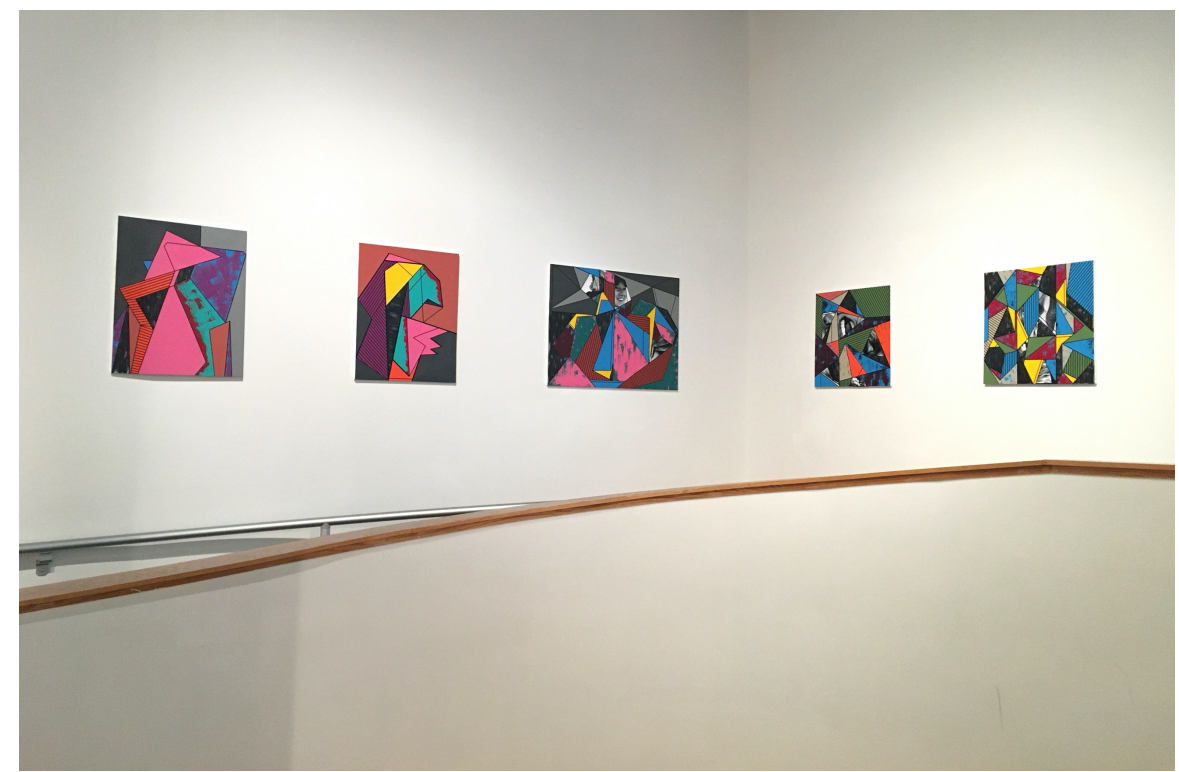

Figure. 2, Olivia Oddo, Disquiet Depictions (installation view). 


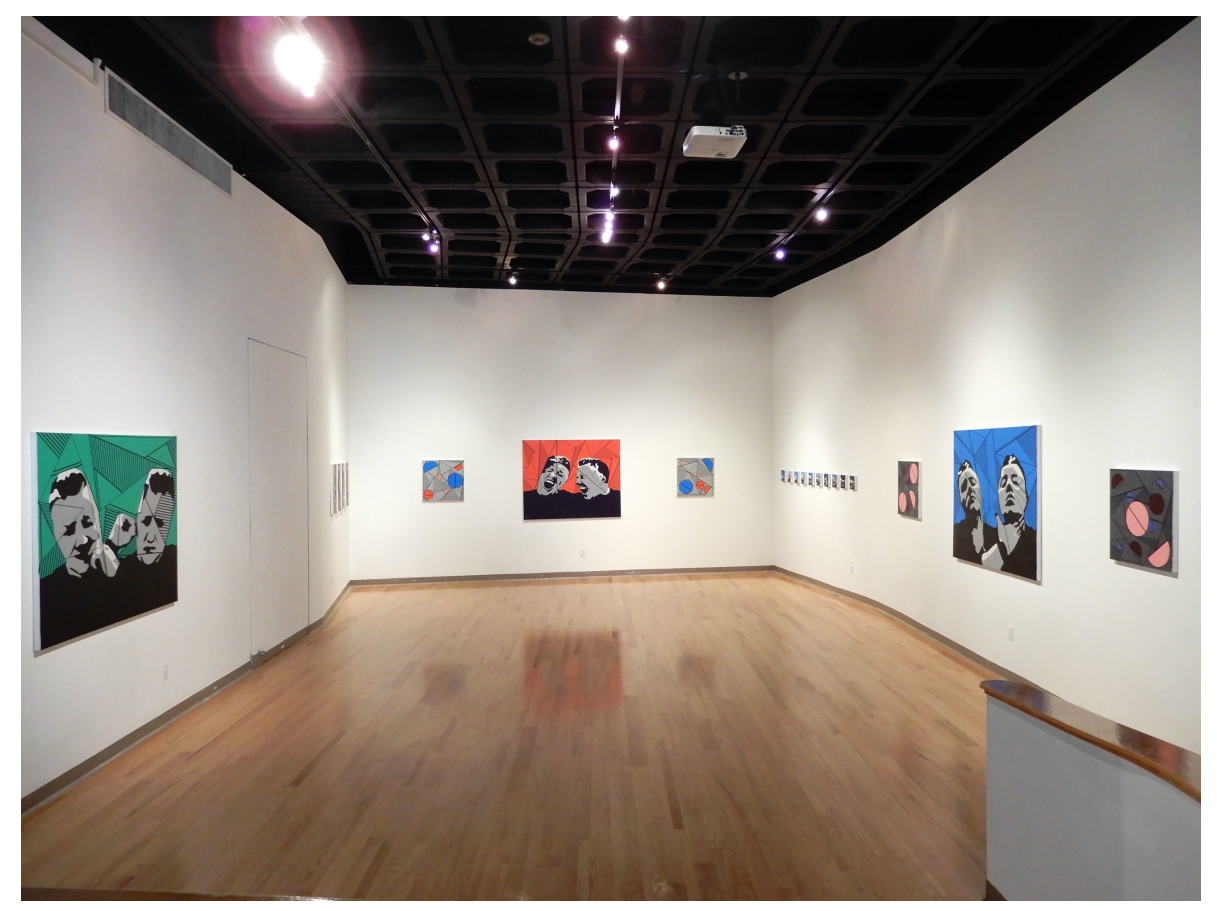

Figure. 3, Olivia Oddo, Disquiet Depictions (installation view).

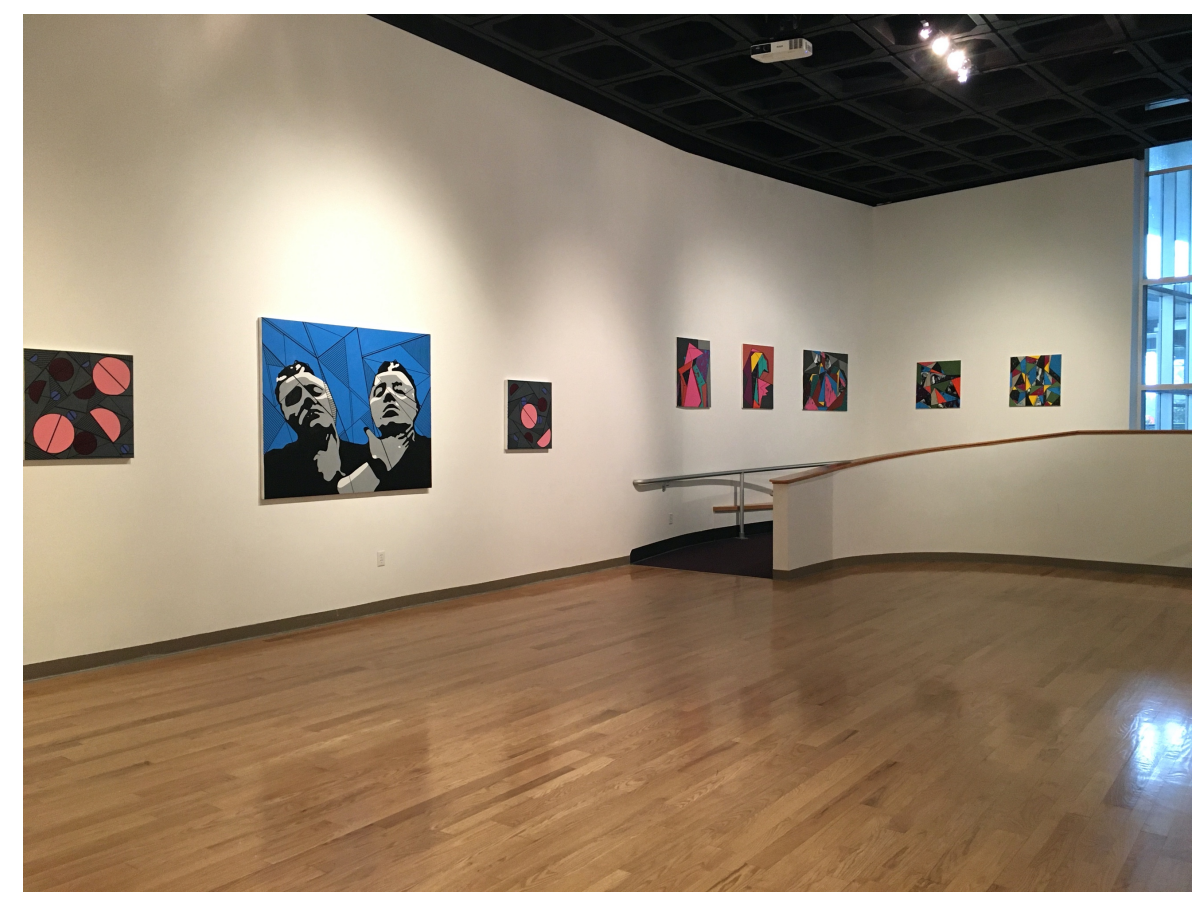

Figure. 4, Olivia Oddo, Disquiet Depictions (installation view). 


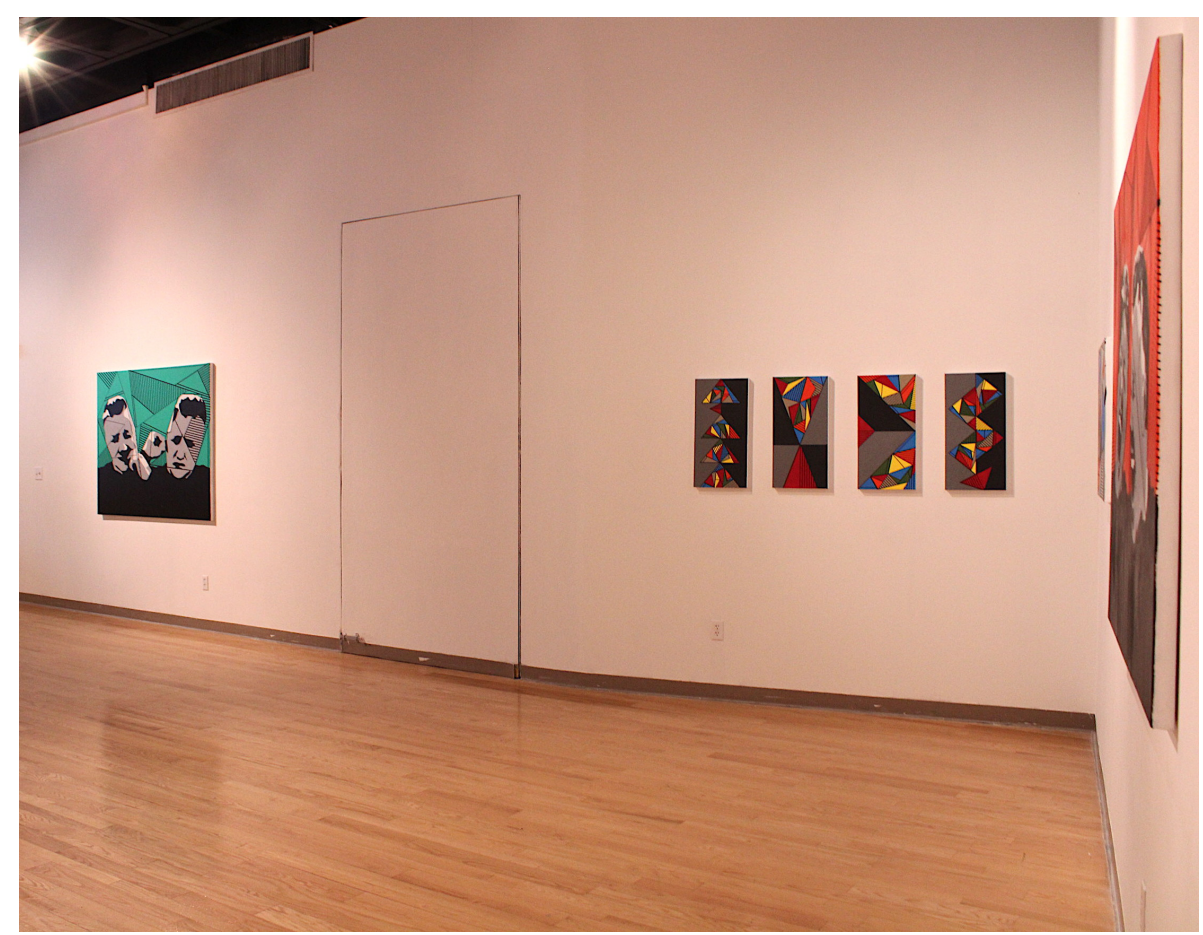

Figure. 5, Olivia Oddo, Disquiet Depictions (installation view).

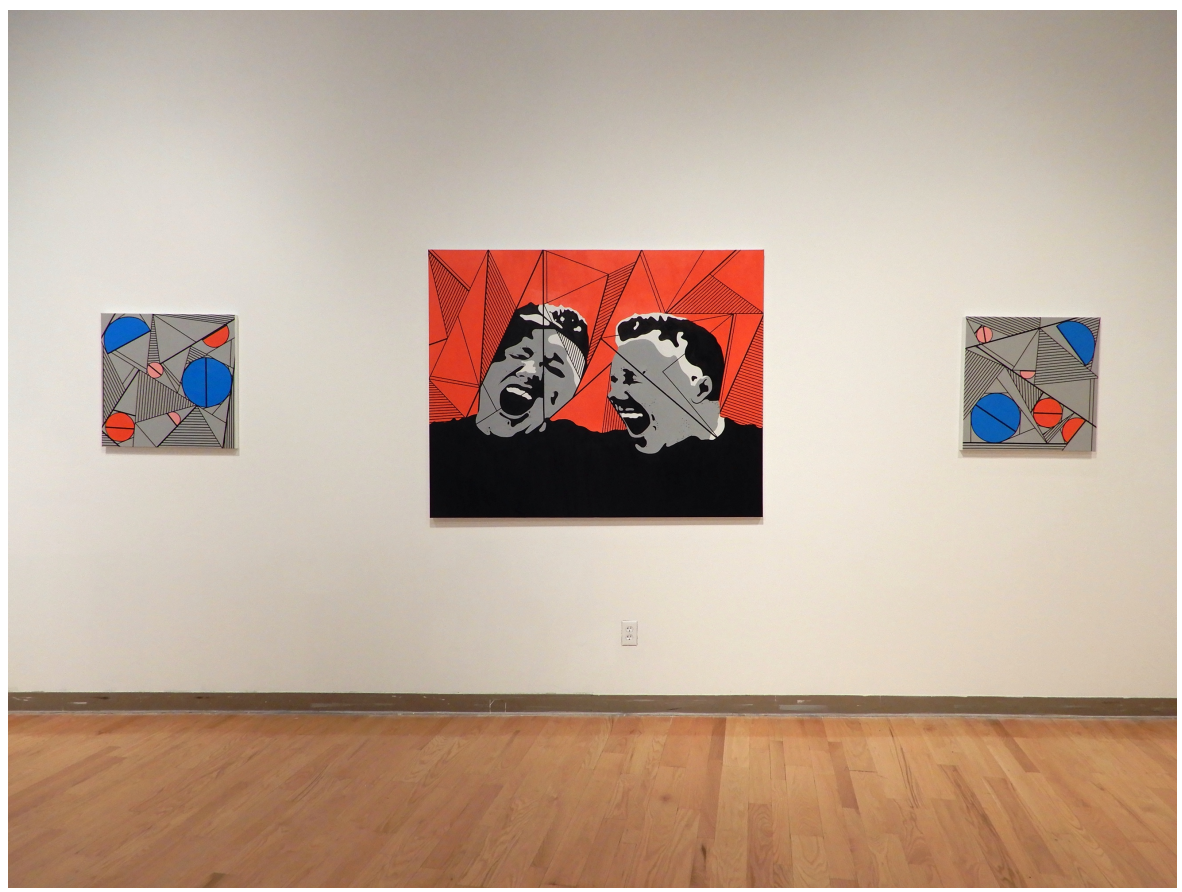

Figure. 6, Olivia Oddo, Disquiet Depictions (installation view). 


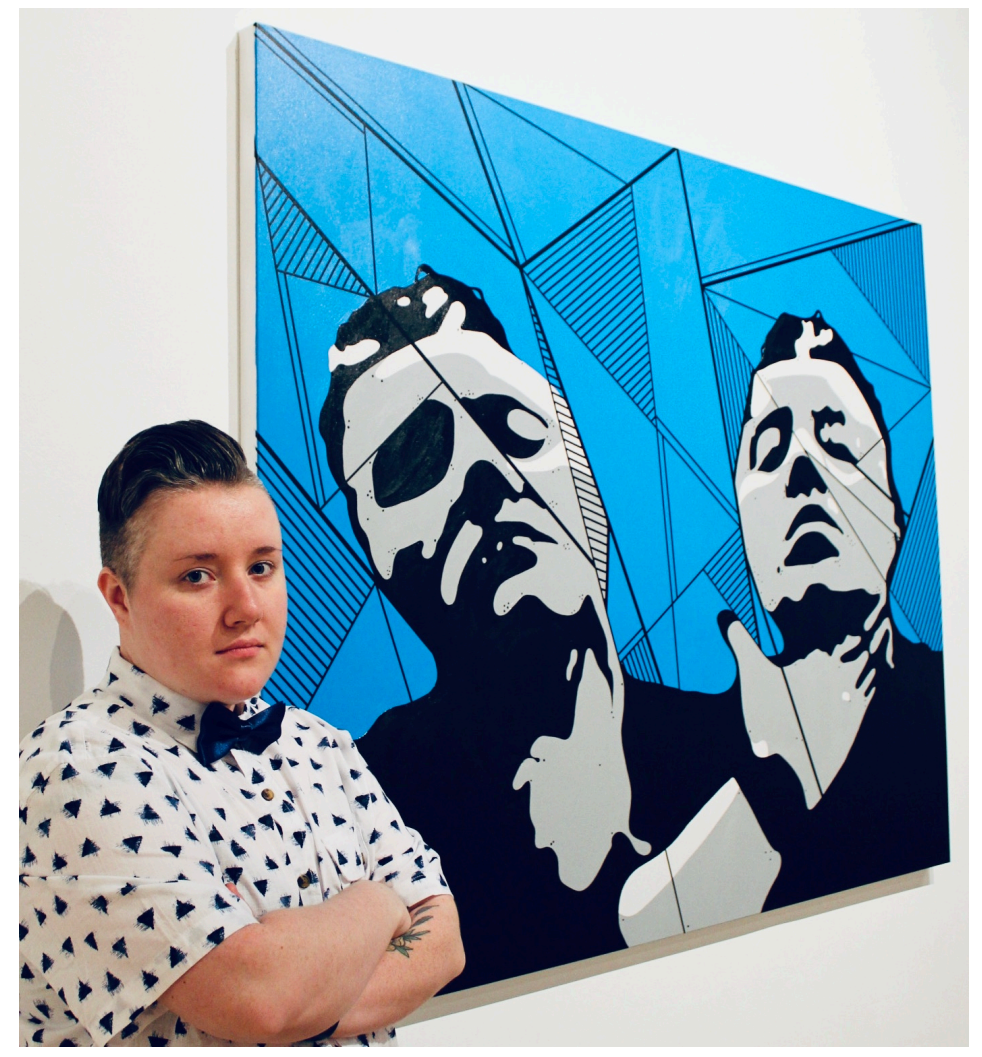

Figure. 7, Olivia Oddo, Disquiet Depictions (artist portrait).

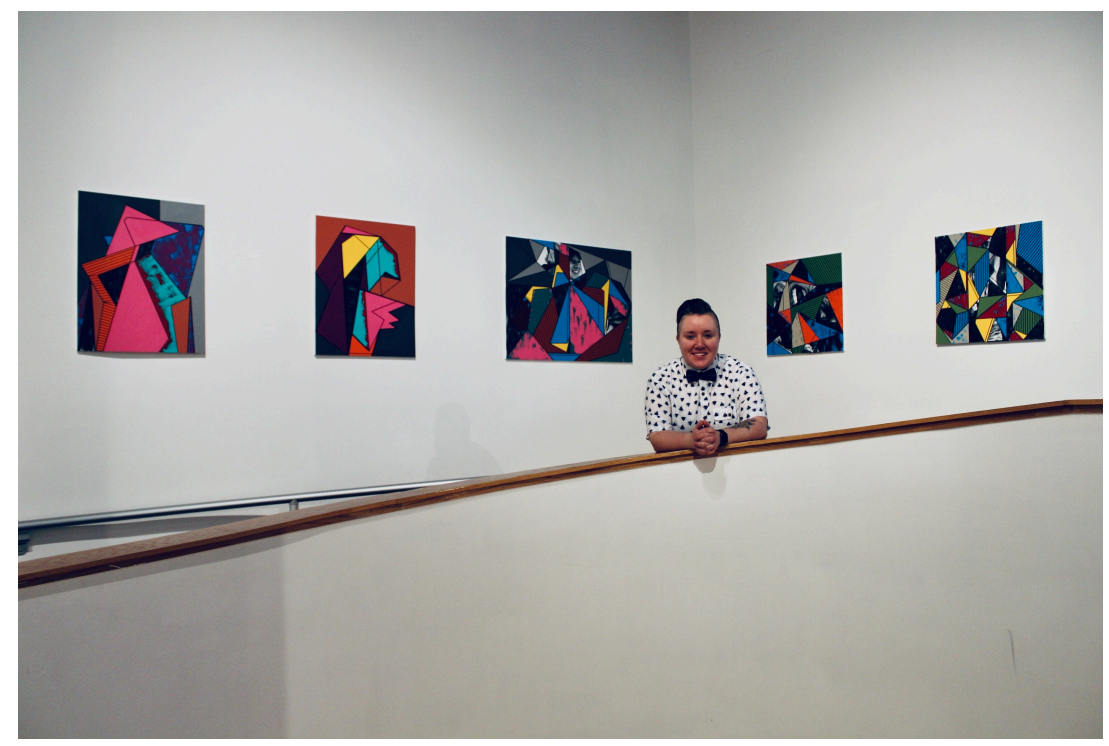

Figure. 8, Olivia Oddo, Disquiet Depictions (artist portrait). 


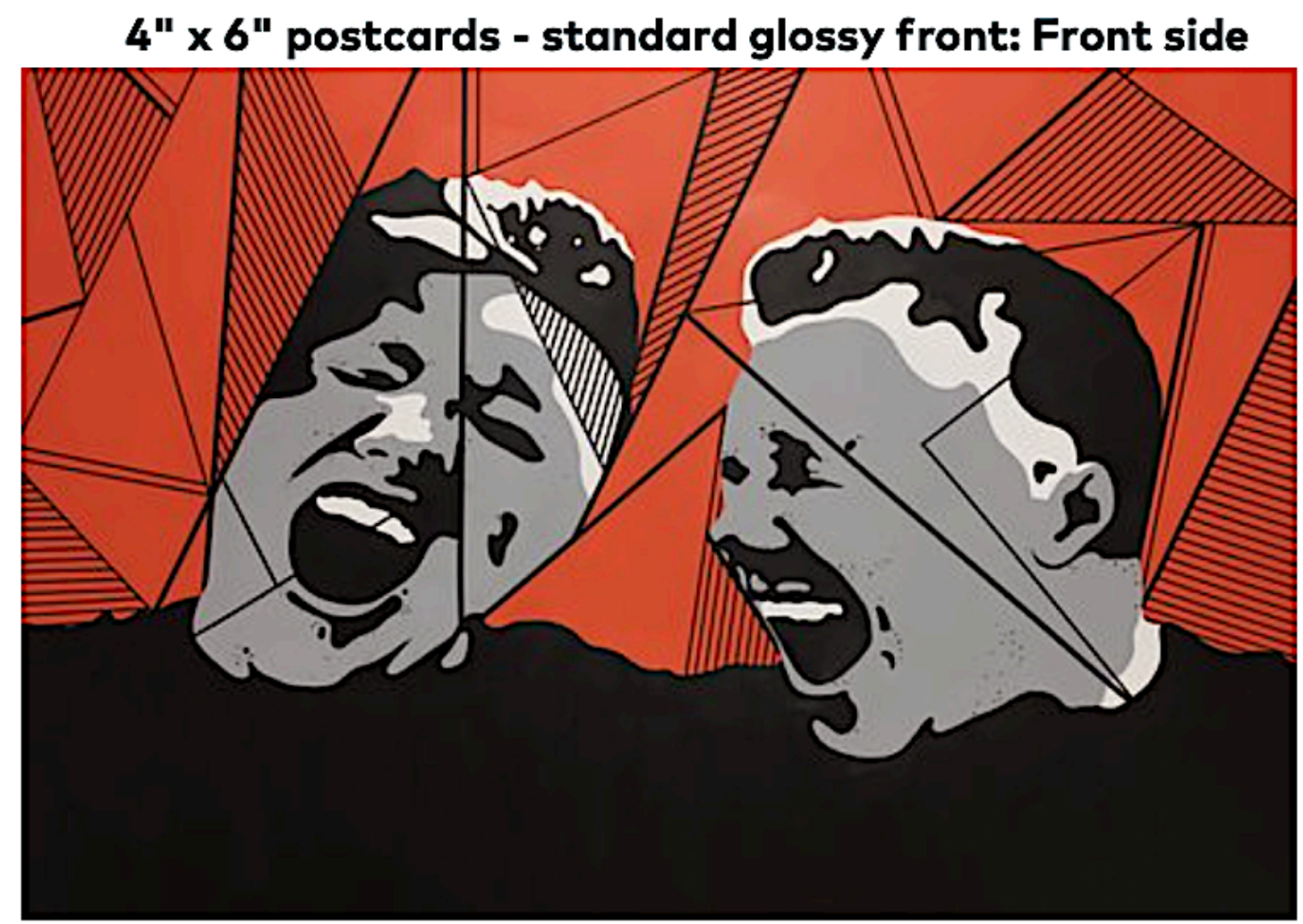

4" x 6" postcards - standard glossy front: Back side

WestVirginiaUniversity.

250023100001

MESAROS CALIERAES

School of Art \& Design

PQ Eox 6111

Morgantown, WV 265066111

artanddesign wruedu

\section{Bisquiet $\$$ epictions}

Olivia Oddo

Master of Fine Arts Thesis Exhibition

March 23 - 26, 2020

Reception: Thursday, March $26,5.6 \mathrm{pm}$.

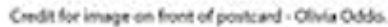

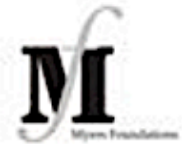

Figure. 9, Olivia Oddo, Disquiet Depictions (exhibition card). 

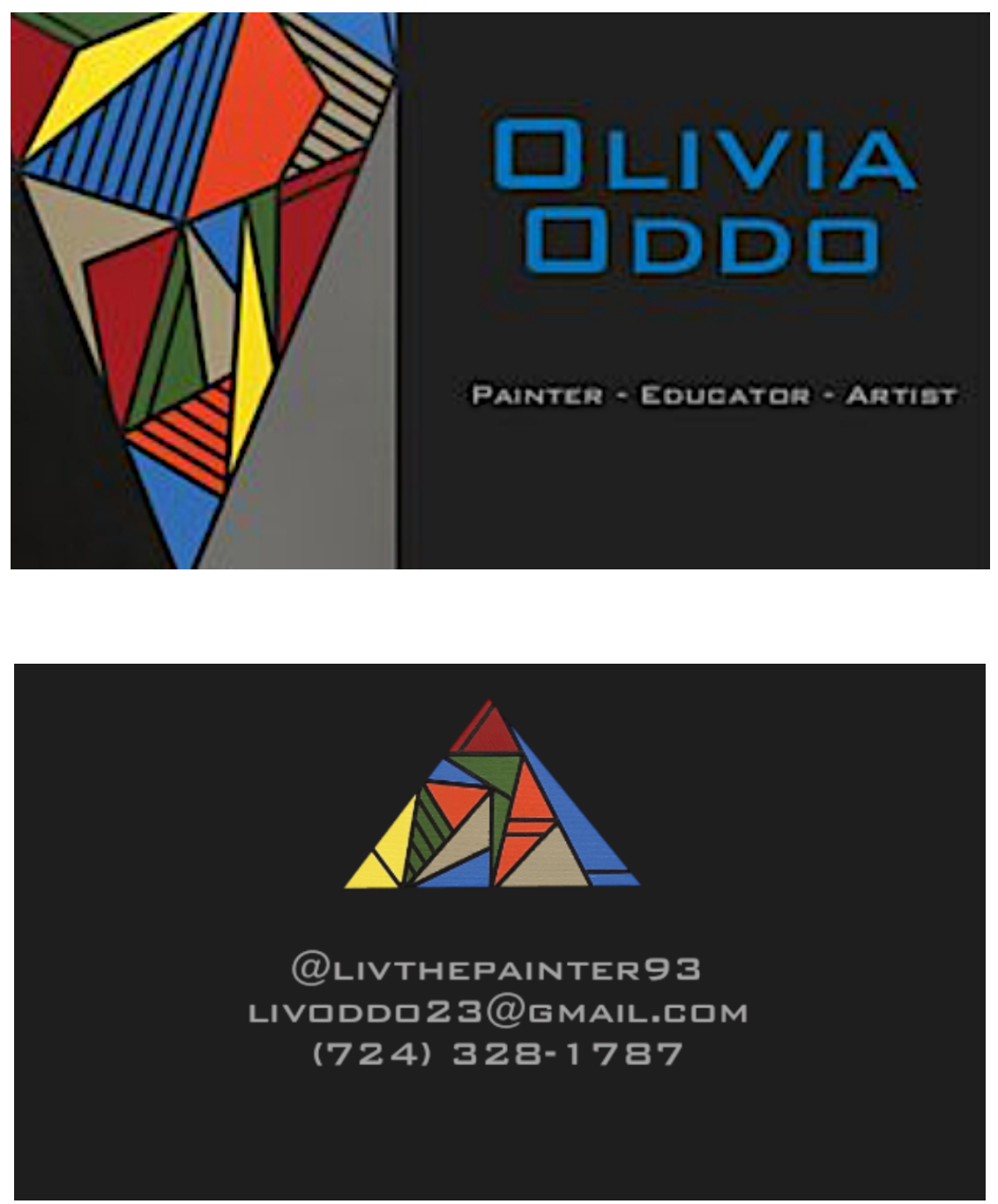

Figure. 10, Olivia Oddo, Disquiet Depictions (business card). 

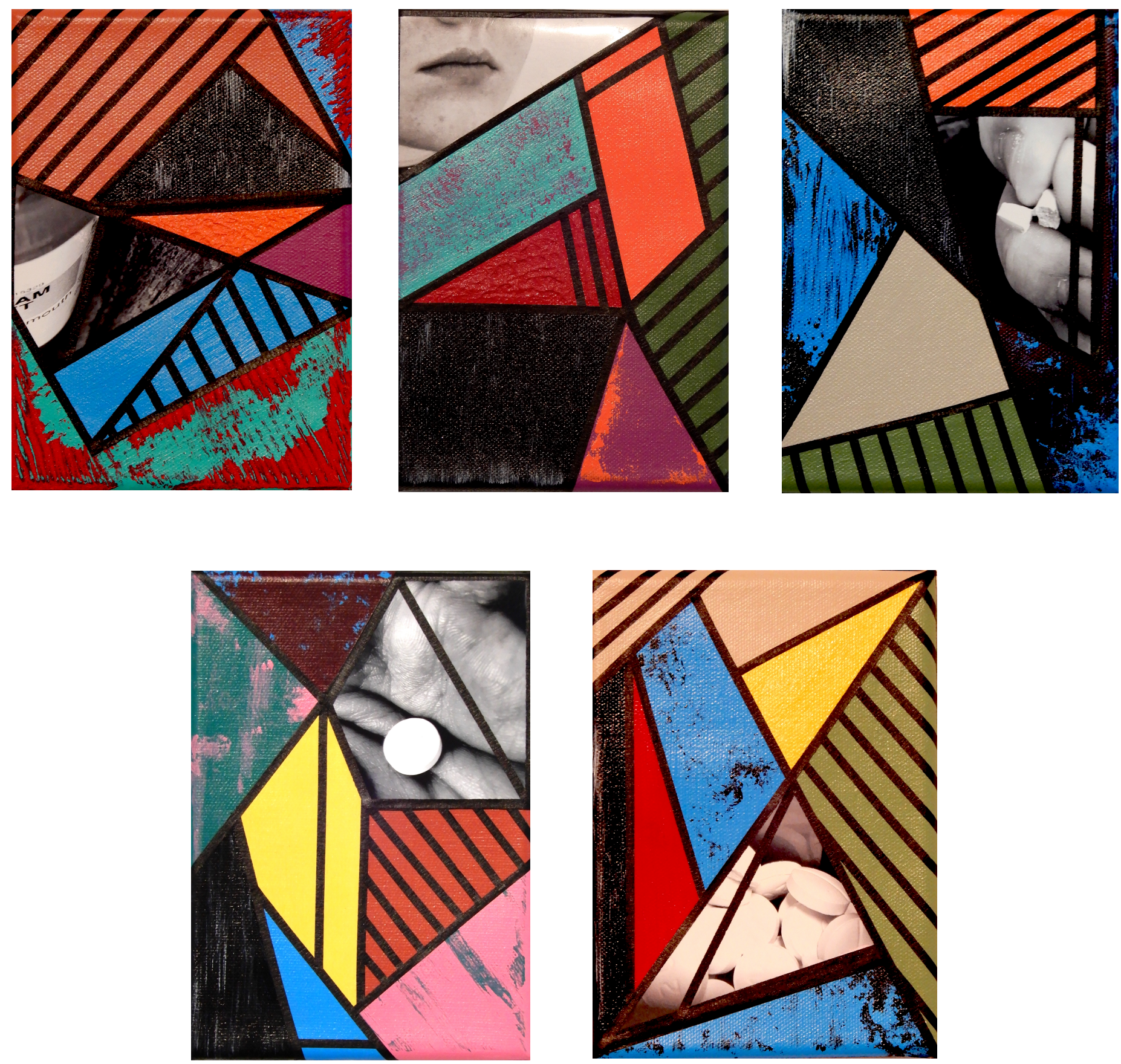

Figure 11. Olivia Oddo, Daily Dose series, Acrylic, Photograph, and Tape on Canvas, 5x7 inches, 2019. 


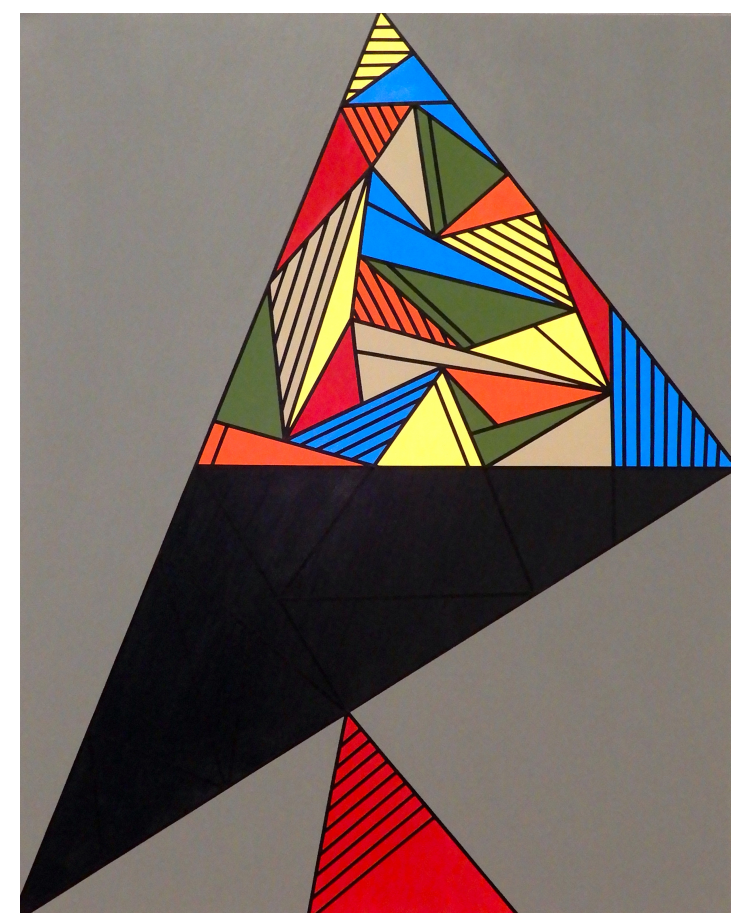

Figure 12. Olivia Oddo, The Dark Side, Acrylic and Tape on Canvas, 24x36 inches, 2020.

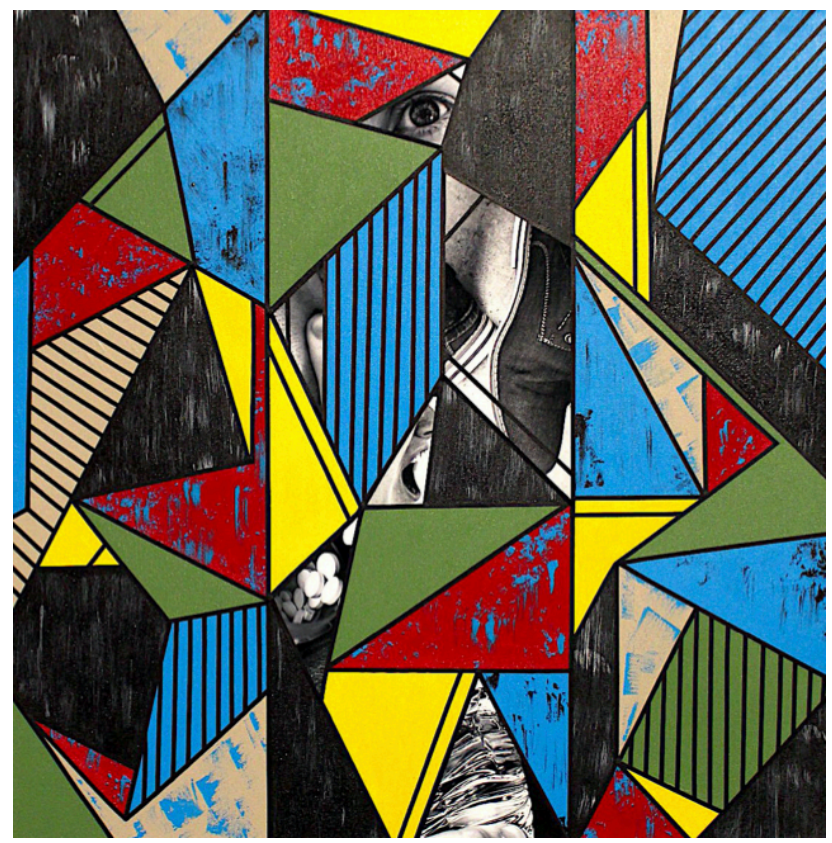

Figure 13. Olivia Oddo, Just Take It, Acrylic, Photograph, and Tape on Canvas, 24x36 inches, 2019. 


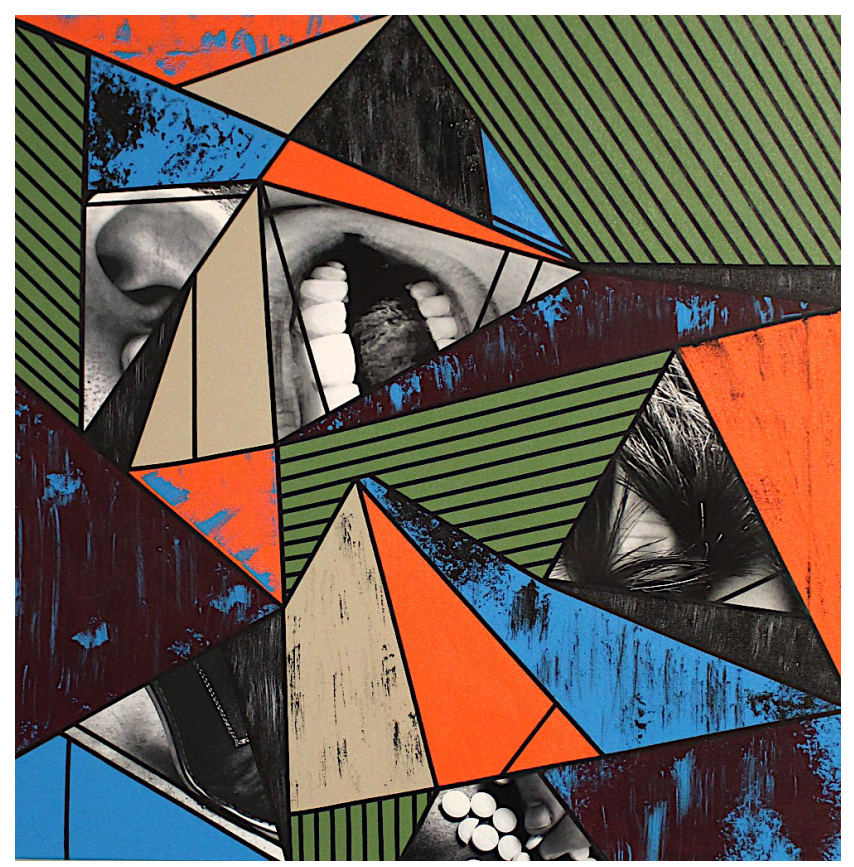

Figure 14. Olivia Oddo, Don't Panic, Acrylic, Photograph, and Tape on Canvas, 24x36 inches, 2019.

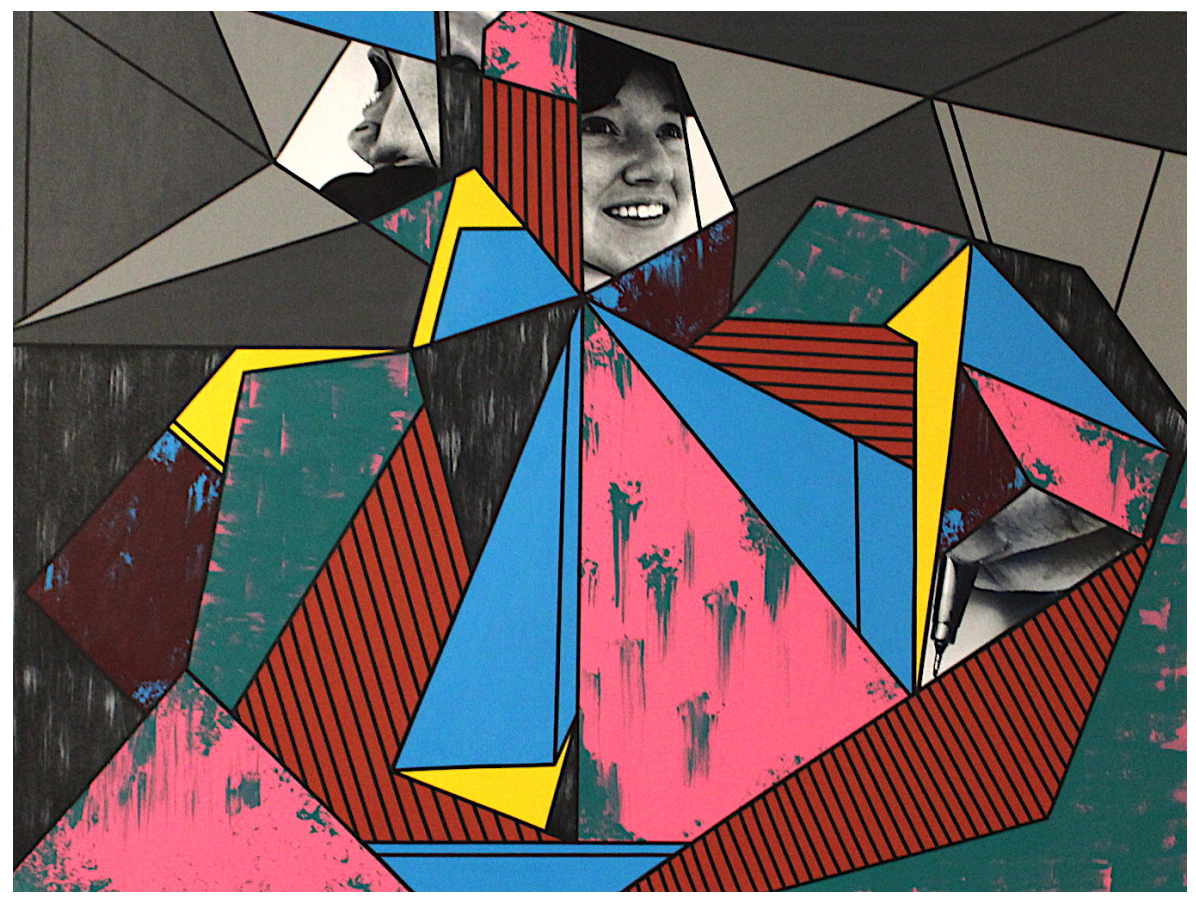

Figure 15. Olivia Oddo, Like Flipping a Coin, Acrylic, Photograph, and Tape on Canvas, 24x48 inches, 2019. 


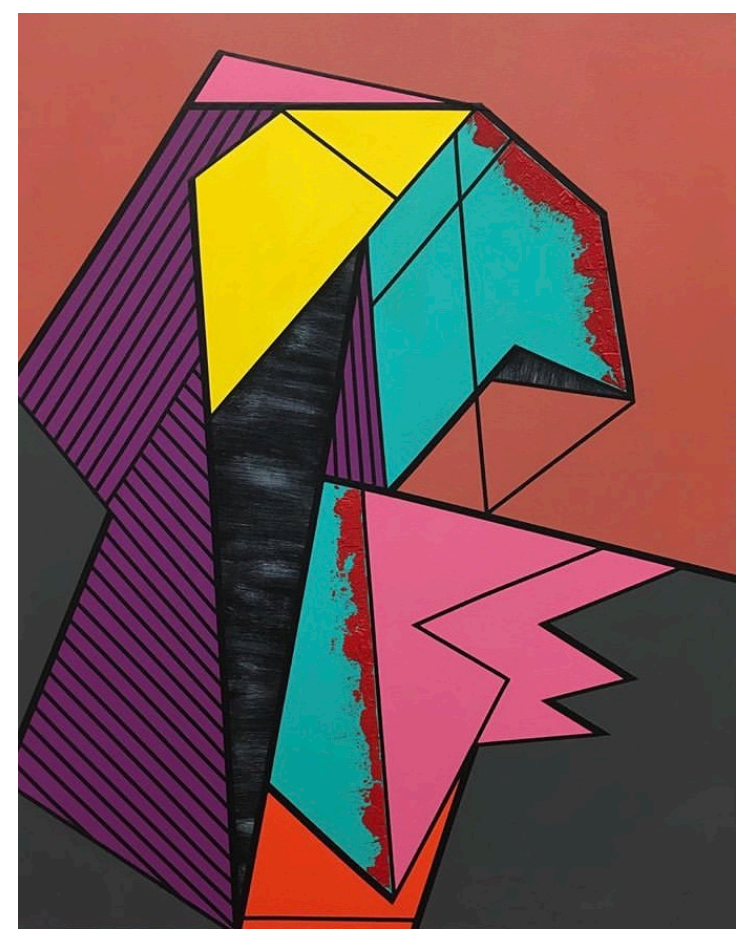

Figure 16. Olivia Oddo, You Tell Me, Acrylic and Tape on Canvas, 24x36 inches, 2019.

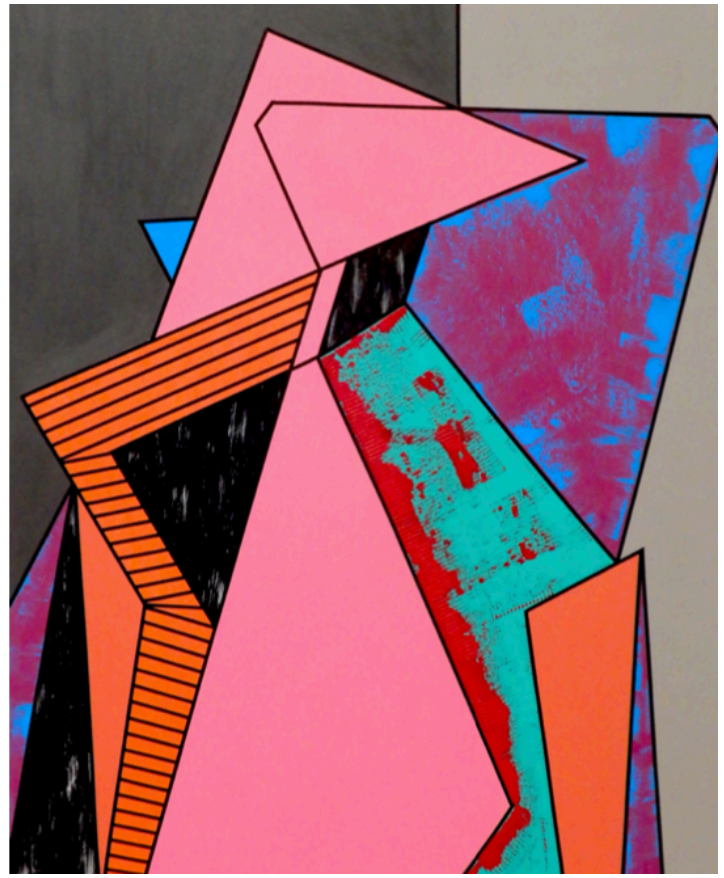

Figure 17. Olivia Oddo, I'm Listening, Acrylic and Tape on Canvas, 24x36 inches, 2019. 


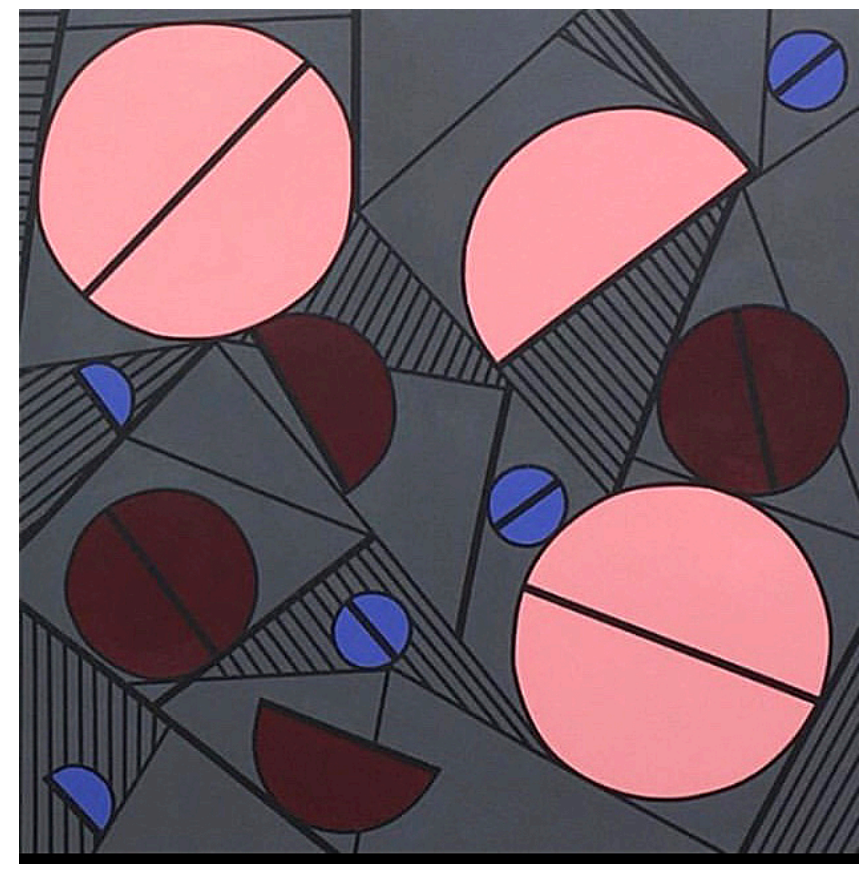

Figure 18. Olivia Oddo, These Will Help 1, Acrylic and Tape on Canvas, 24x36 inches, 2020.

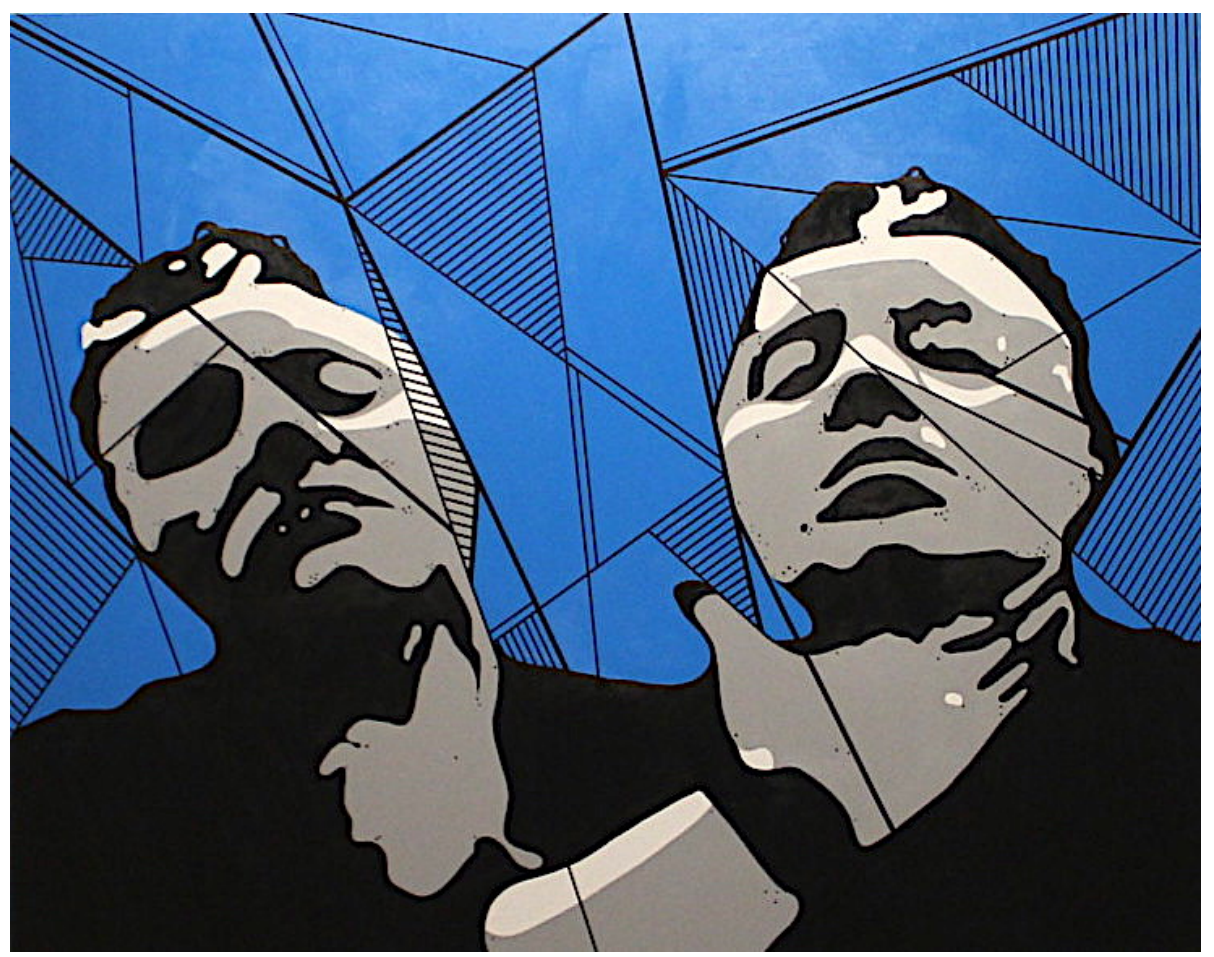

Figure 19. Olivia Oddo, Do You Feel It?, Acrylic and Tape on Canvas, 48x60 inches, 2020. 


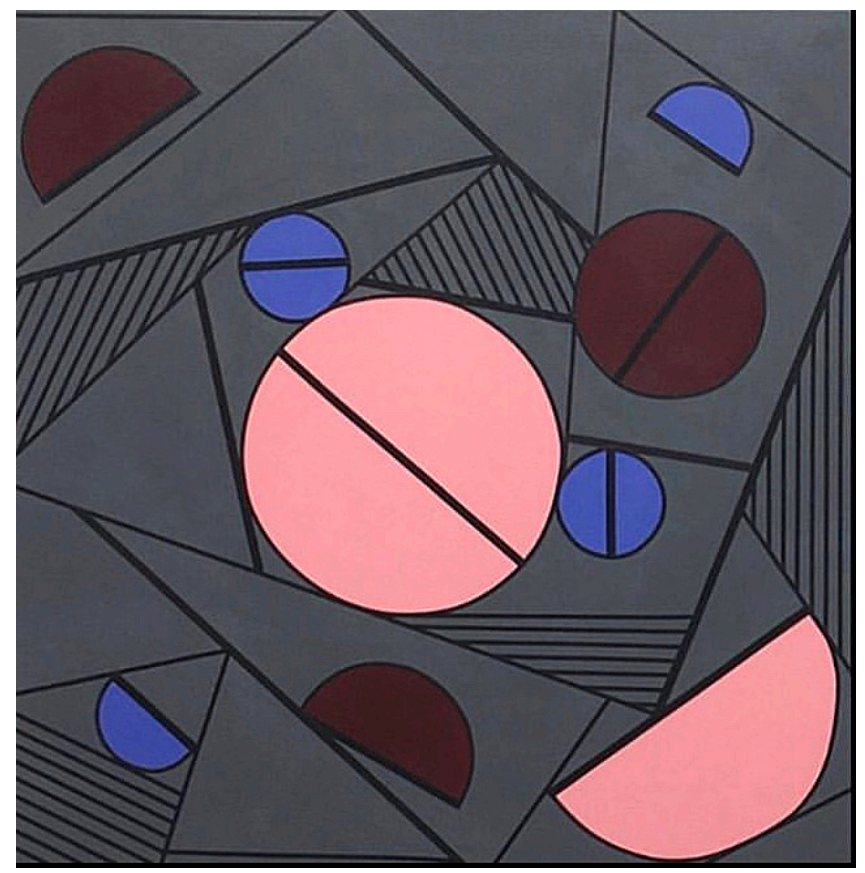

Figure 20. Olivia Oddo, These Will Help 2, Acrylic and Tape on Canvas, 24x36 inches, 2020.

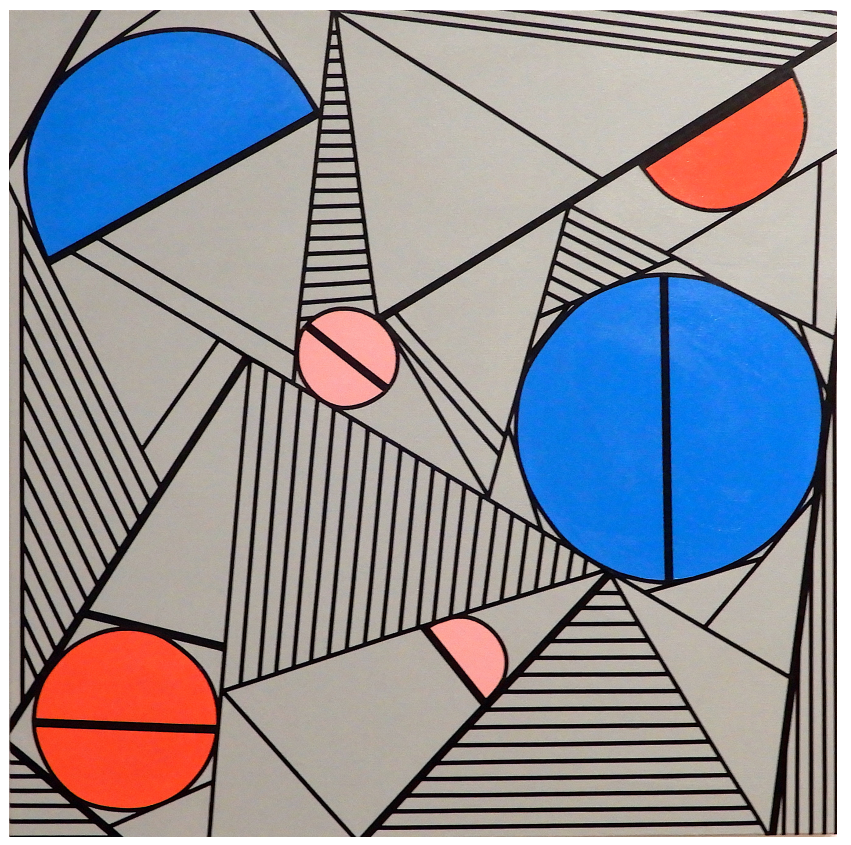

Figure 21. Olivia Oddo, These Will Help 3, Acrylic and Tape on Canvas, 24x36 inches, 2020. 


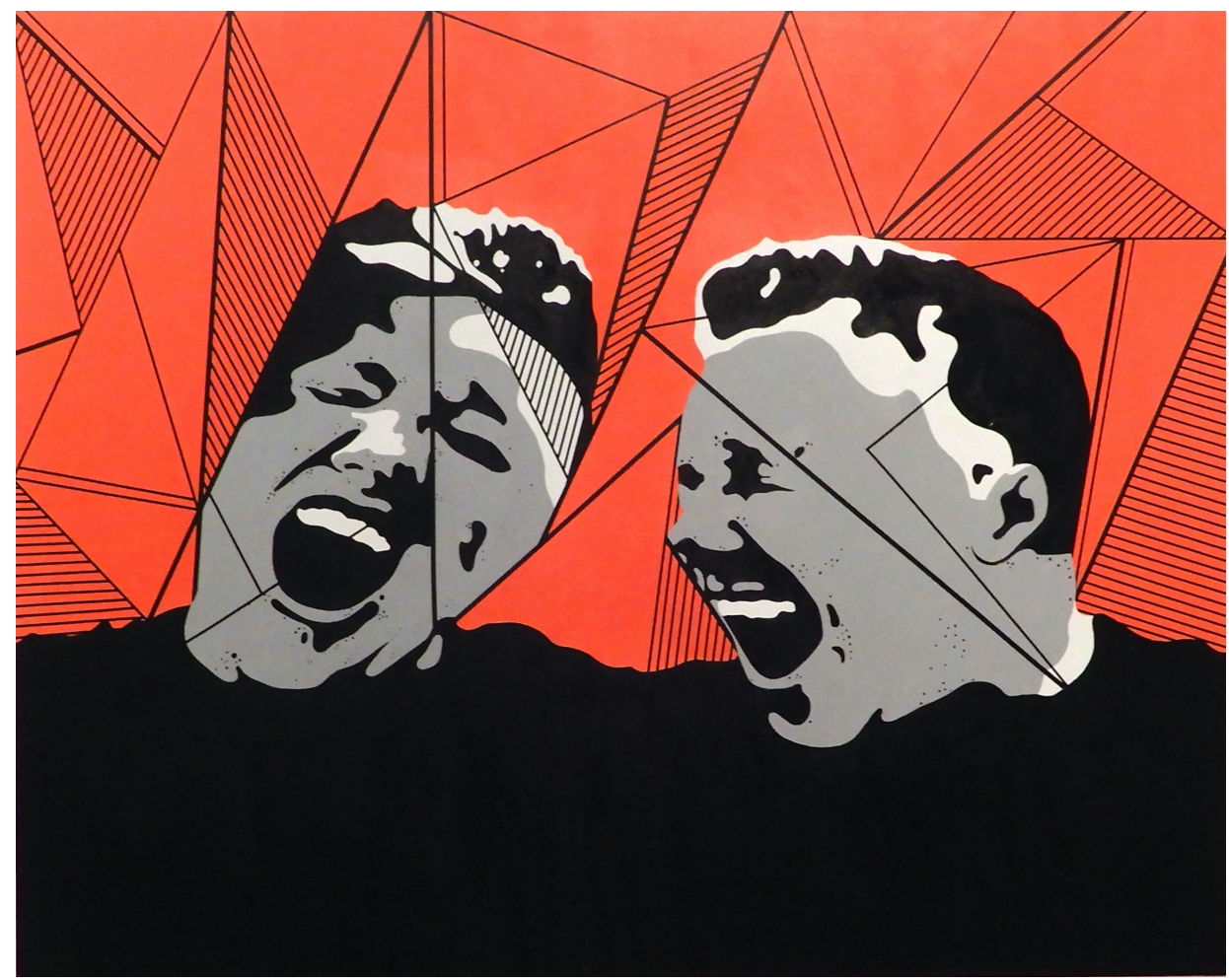

Figure 22. Olivia Oddo, Just Let It Out, Acrylic and Tape on Canvas, 48x60 inches, 2020.

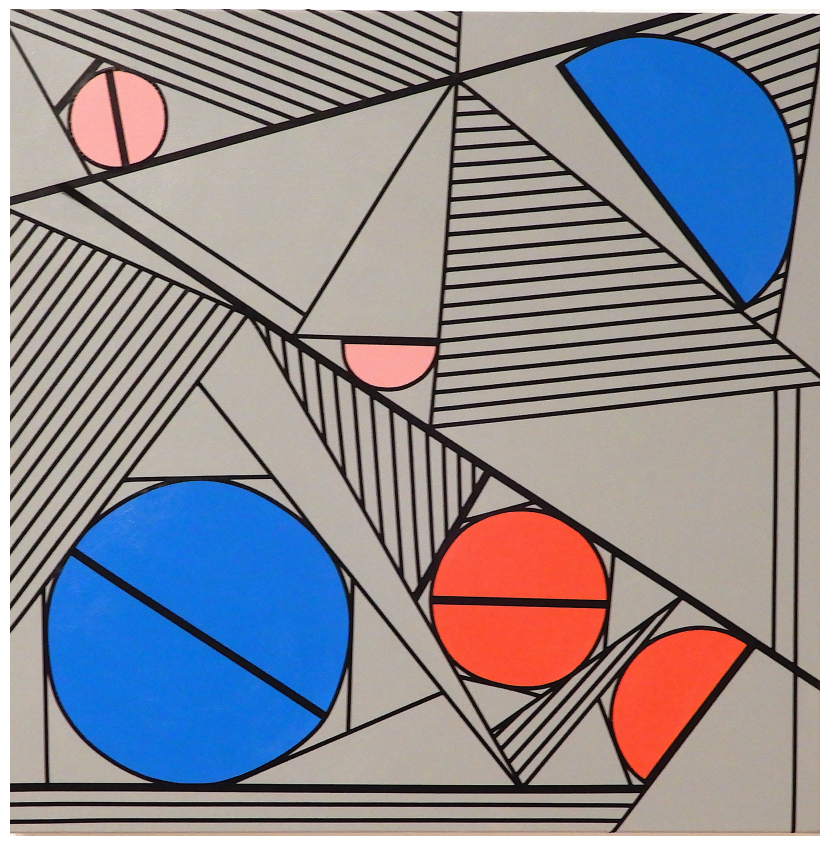

Figure 23. Olivia Oddo, These Will Help 4, Acrylic and Tape on Canvas, 24x36 inches, 2020. 


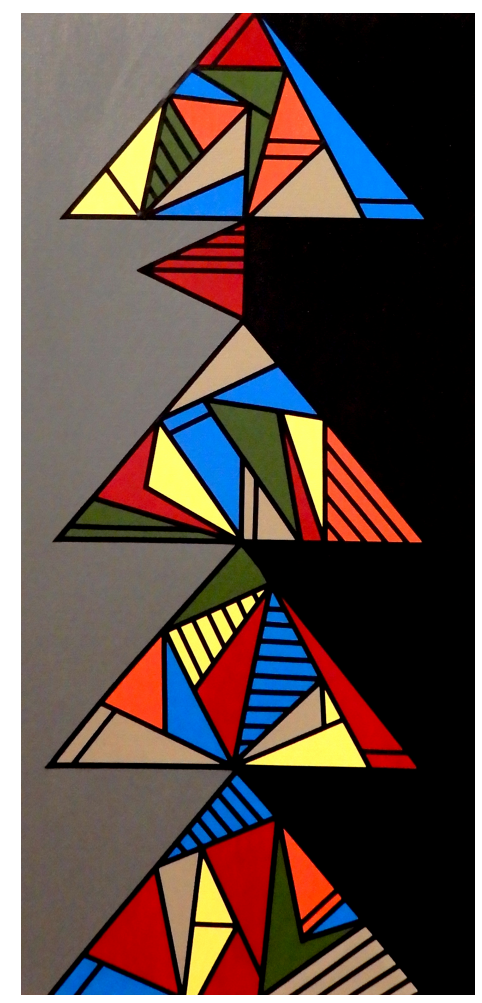

Figure 24. Olivia Oddo, It's Noticeable, Acrylic and Tape on Canvas, $12 \times 24$ inches, 2020.

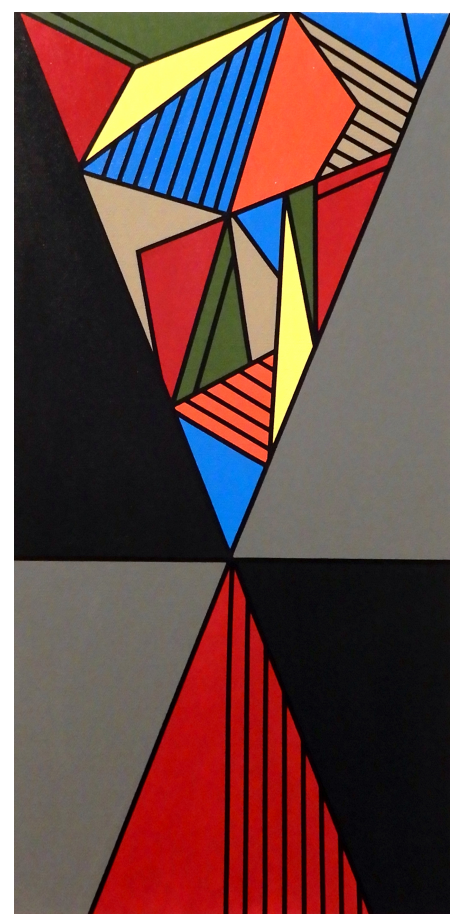

Figure 25. Olivia Oddo, Winding Down, Acrylic and Tape on Canvas, 12x24 inches, 2020. 


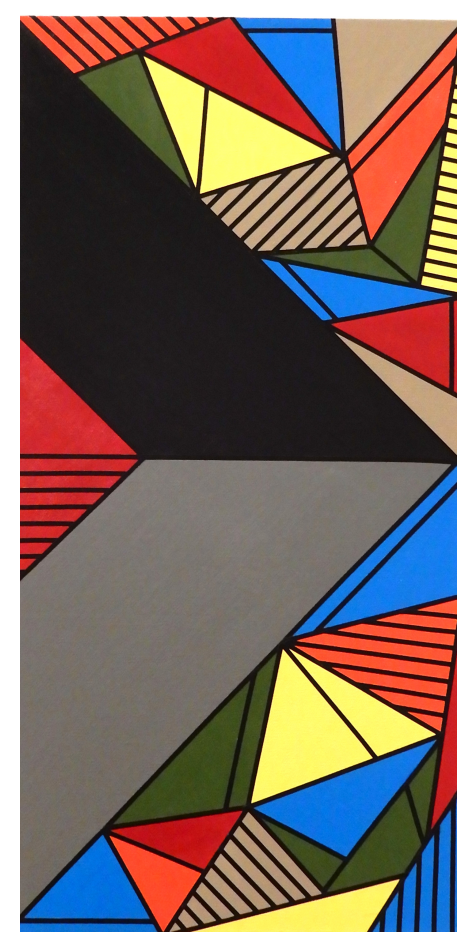

Figure 26. Olivia Oddo, Too Many, Acrylic and Tape on Canvas, 12x24 inches, 2020.

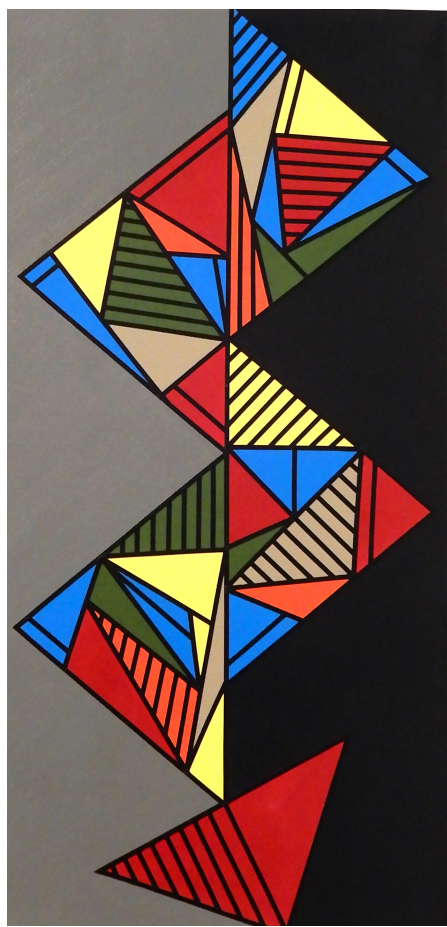

Figure 27. Olivia Oddo, Pacing Helps, Acrylic and Tape on Canvas, 12x24 inches, 2020. 

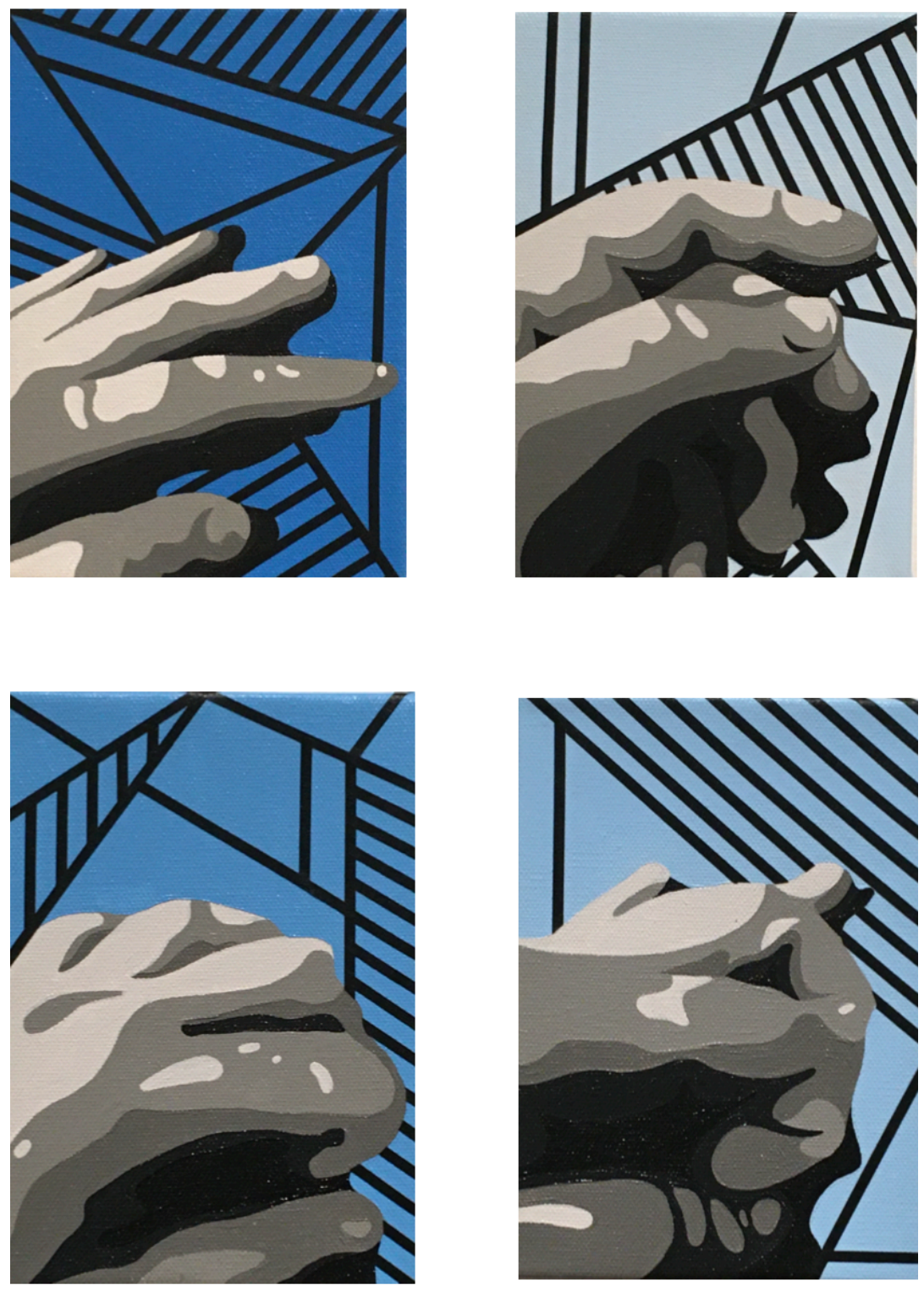

Figure 28. Olivia Oddo, Picking on Me series, Acrylic and Tape on Canvas, 5x7 inches, 2020. 

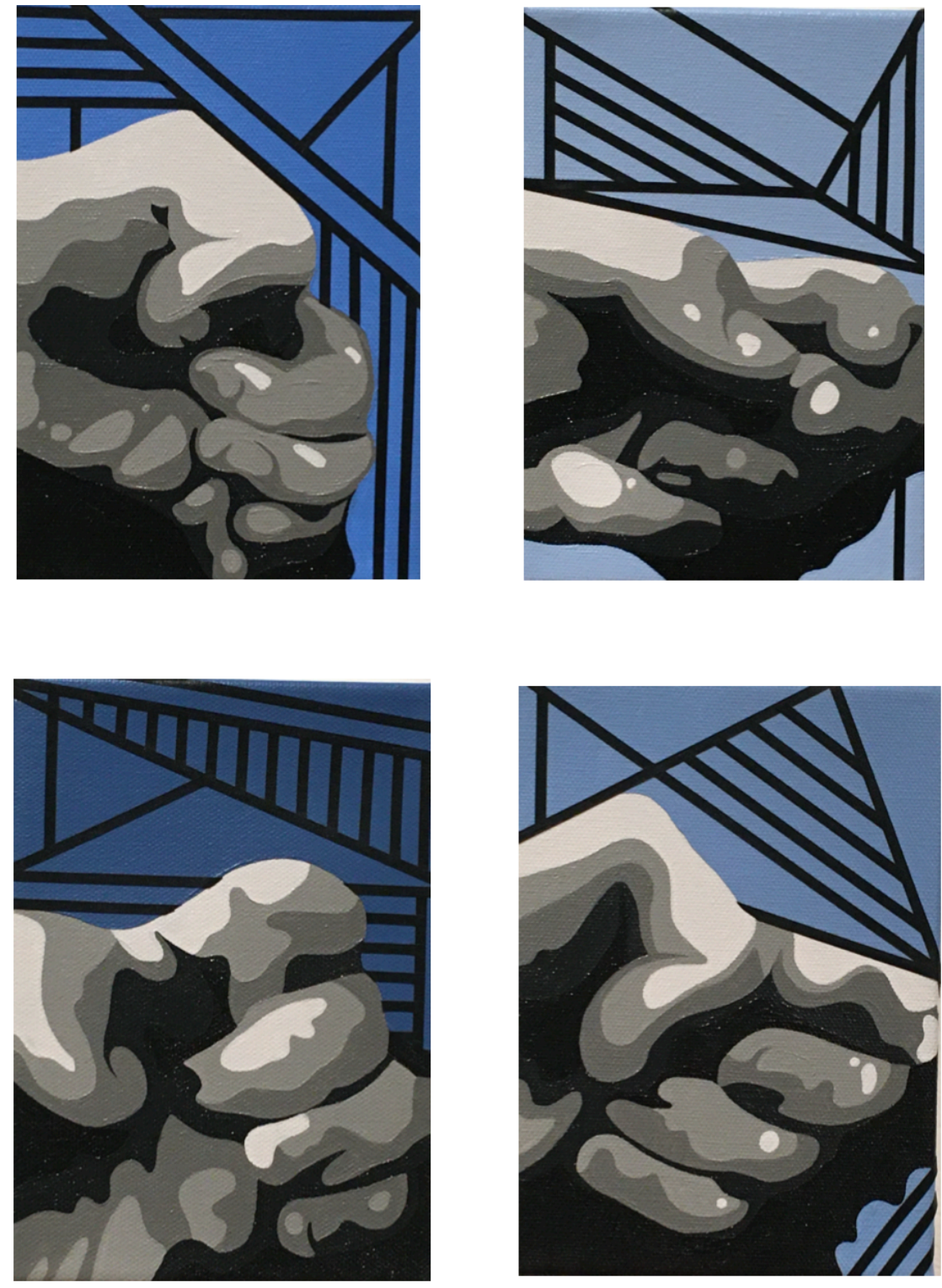

Figure 29. Olivia Oddo, Picking on Me series, Acrylic and Tape on Canvas, 5x7 inches, 2020. 

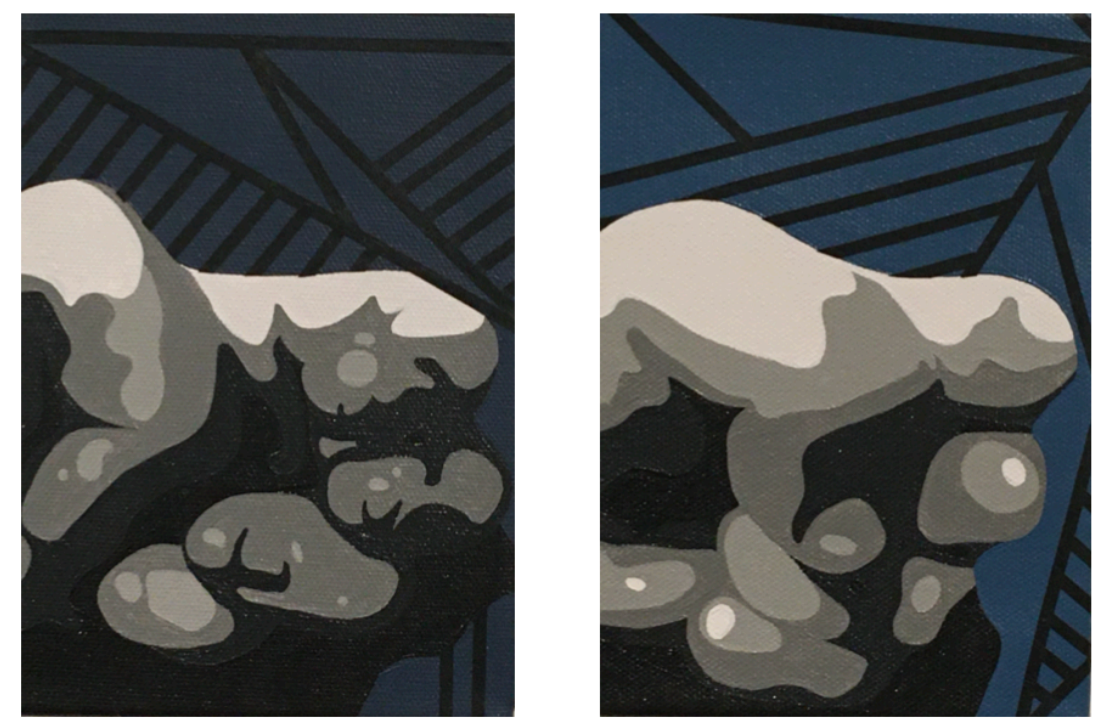

Figure 30. Olivia Oddo, Picking on Me series, Acrylic and Tape on Canvas, 5x7 inches, 2020.

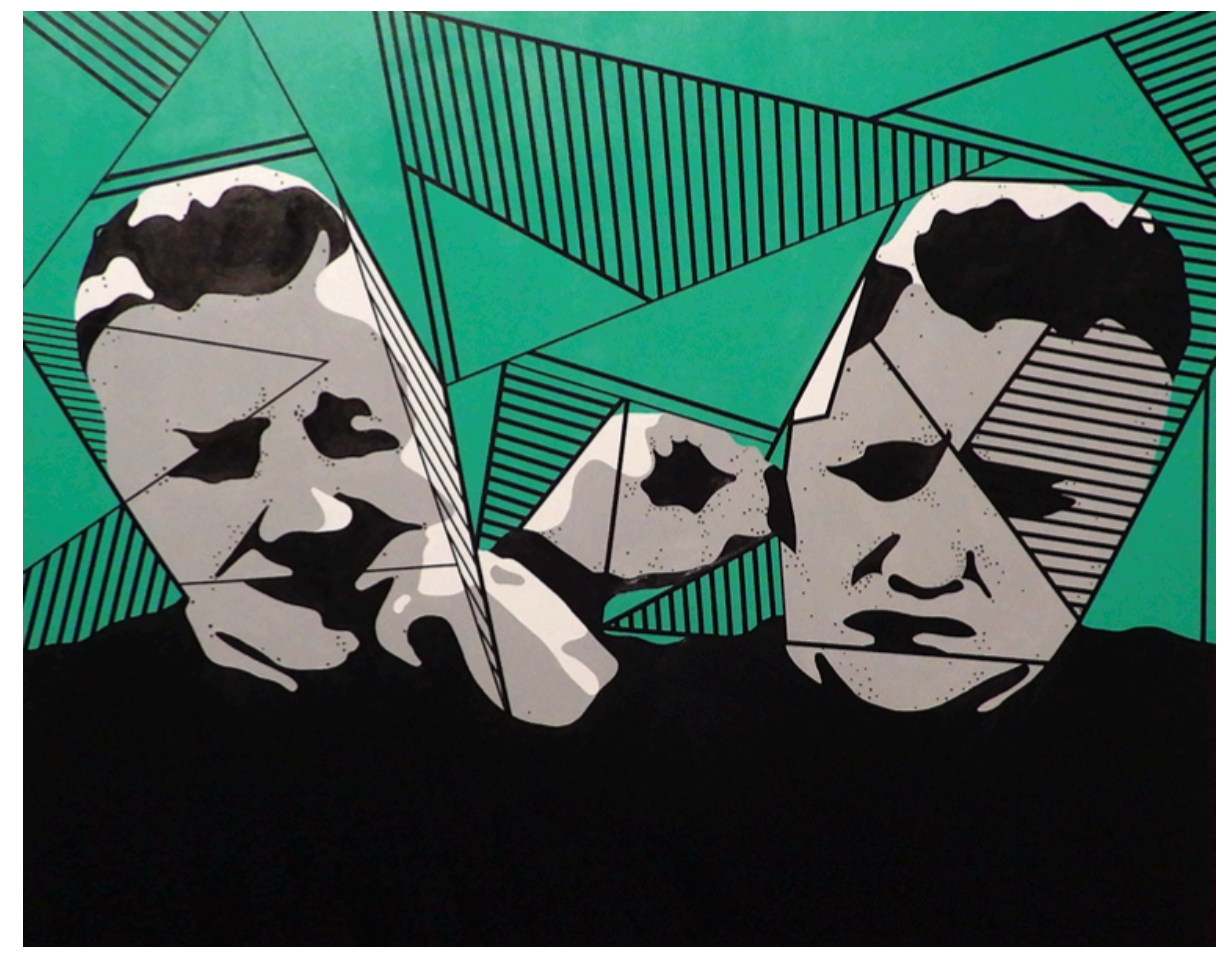

Figure 31. Olivia Oddo, You Need to Stop, Acrylic and Tape on Canvas, 48x60 inches, 2020. 


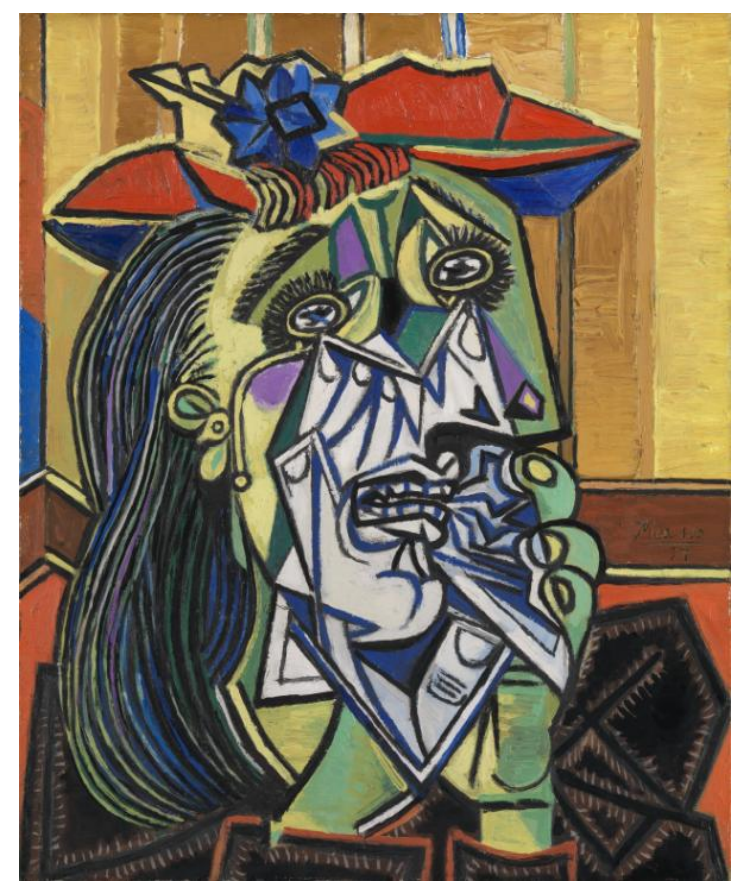

Figure 32. Pablo Picasso, Weeping Woman, Oil on Canvas, 23.6x19.2 inches, 1937.

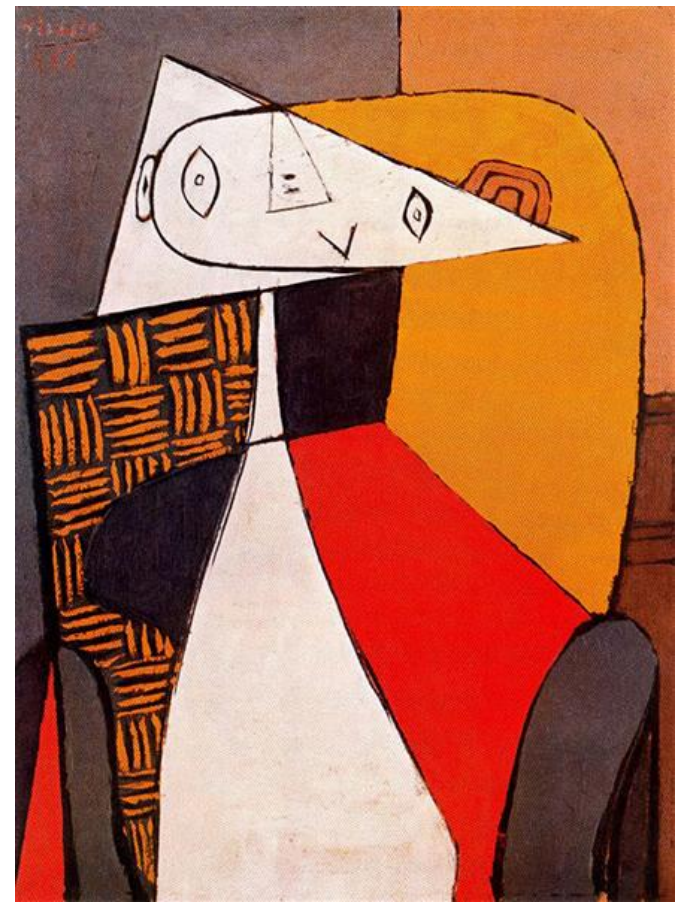

Figure 33. Pablo Picasso, Seated Woman, Oil on Canvas, 23.6x19.2 inches, 1930. 


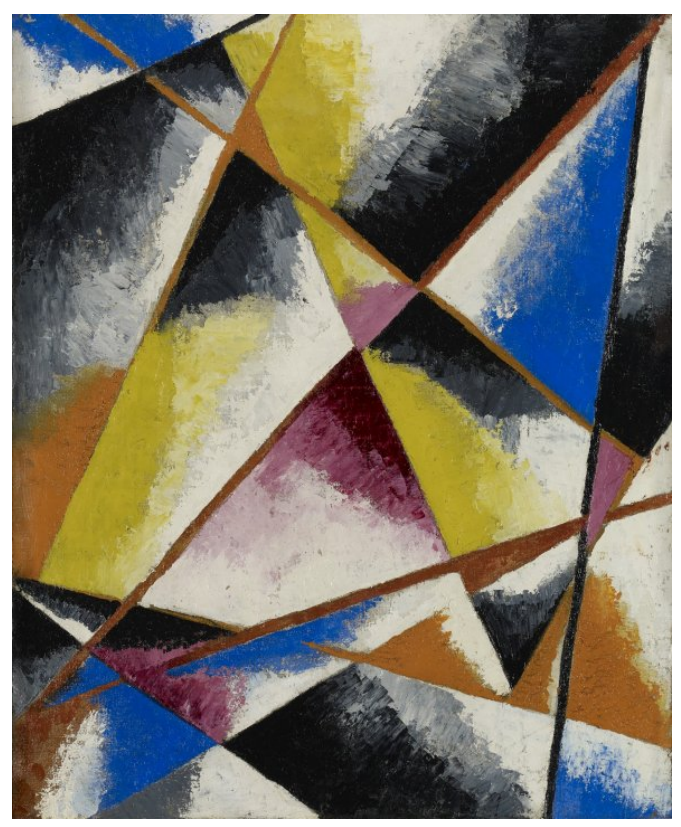

Figure 34. Lyubov' Popova, Untitled Composition, Oil on Canvas, 19.2x15.5 inches, 1916.

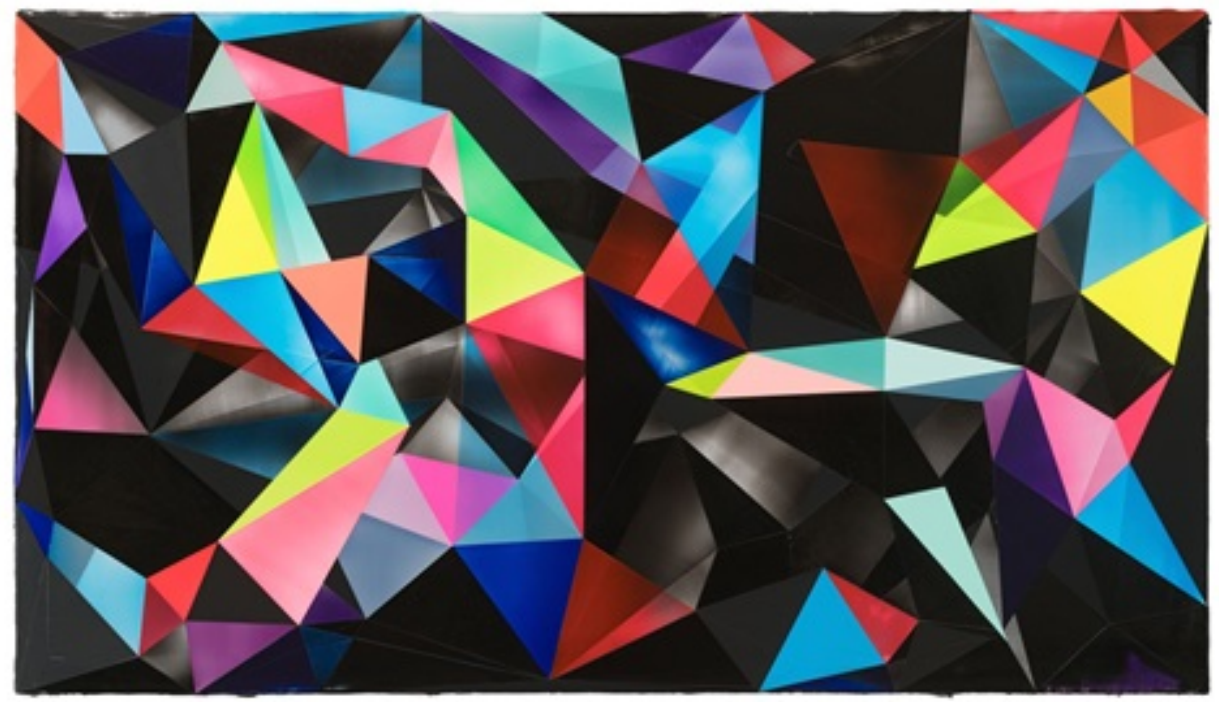

Figure 35. Shannon Finley, torrent 01-19, Acrylic on Canvas, 31.4x55 inches, 2019. 


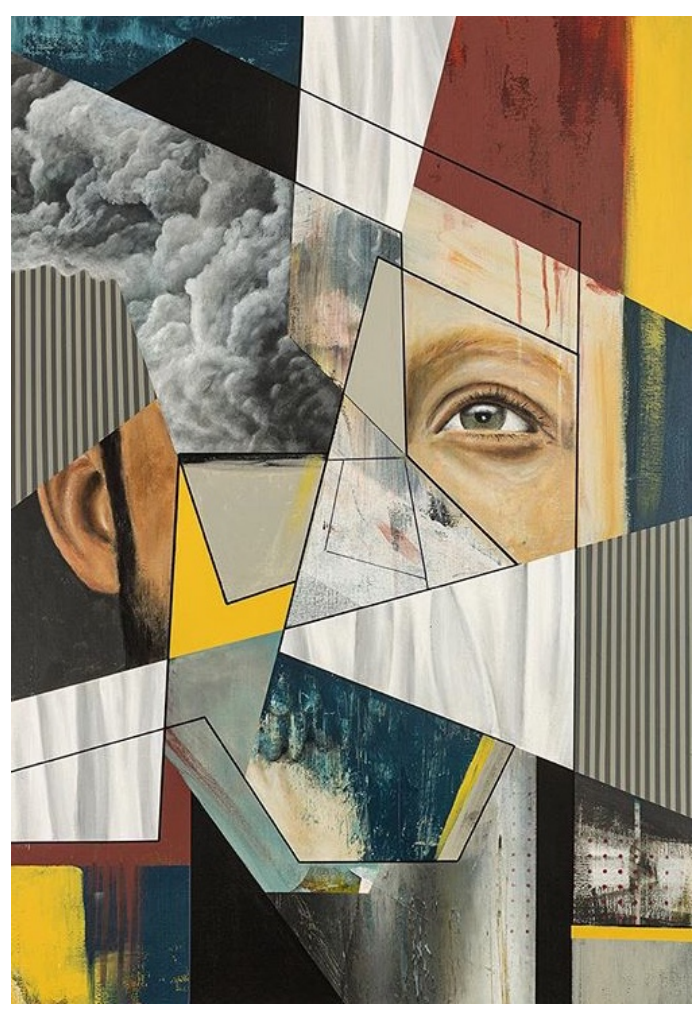

Figure 36. Stefaan De Croock, This was so bloody obvious, Acrylic, Spray Paint, and Markers on Canvas, 27.5x39.3 inches, 2015.

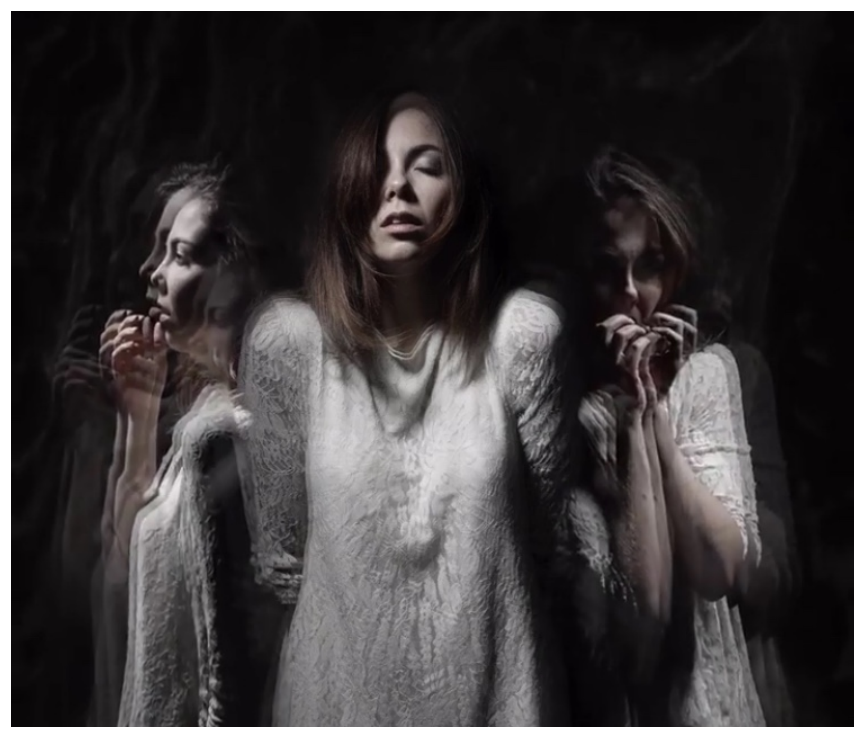

Figure 37. Sarah Wearn, An anxious mind, Digital Photograph, 2018. 


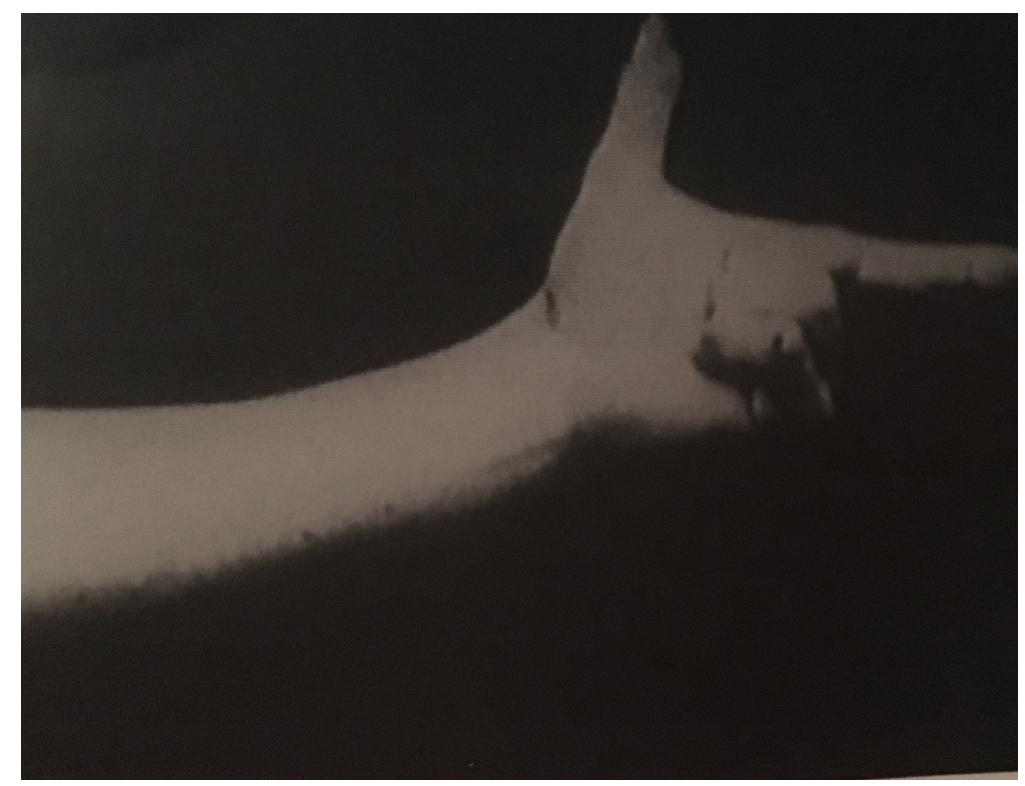

Figure 38. Douglas Gordon, Trigger Finger, Video Installation, 1995.

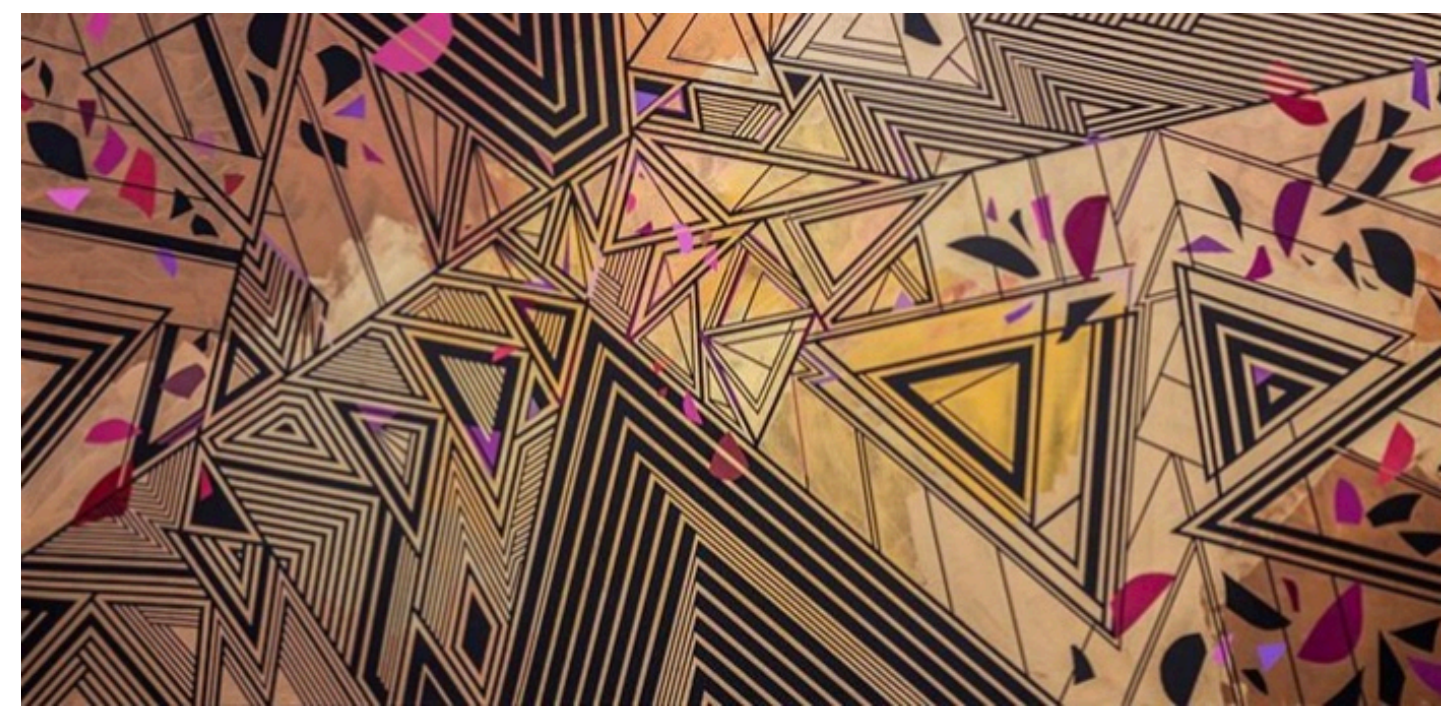

Figure 39. Rae Heller, How We Speak To Each Other, Acrylic on Canvas, 36x72 inches, 2020. 


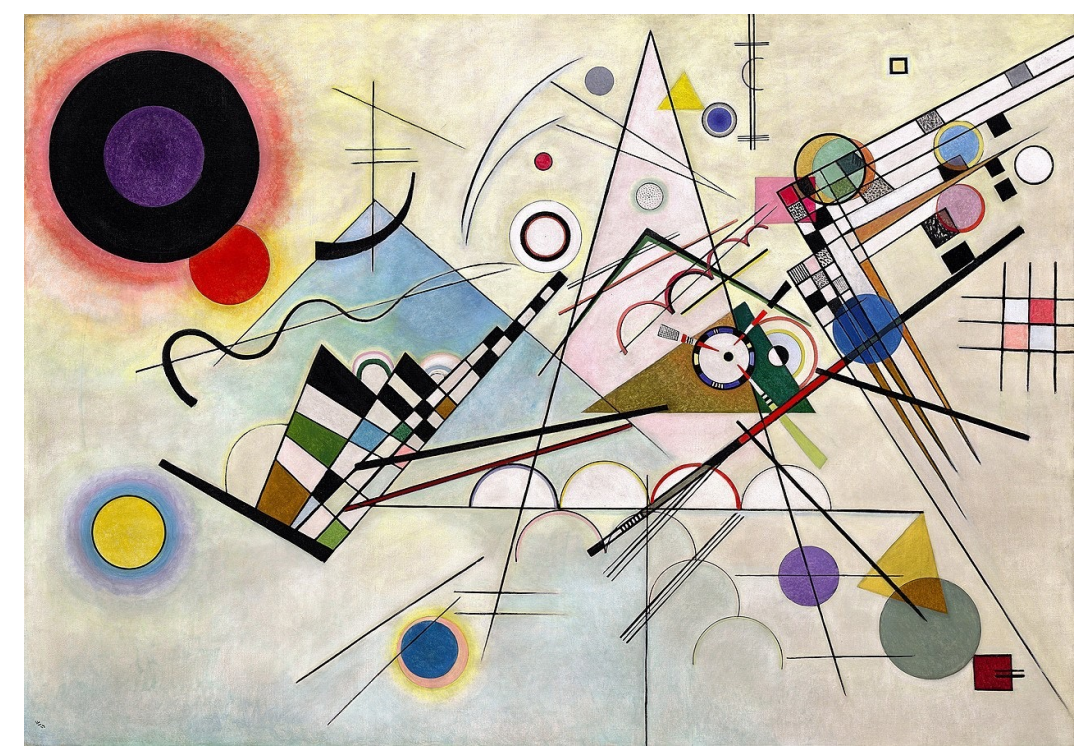

Figure 40. Wassily Kandinsky, Composition VIII, Oil on Canvas, 55x79 inches, 1923.

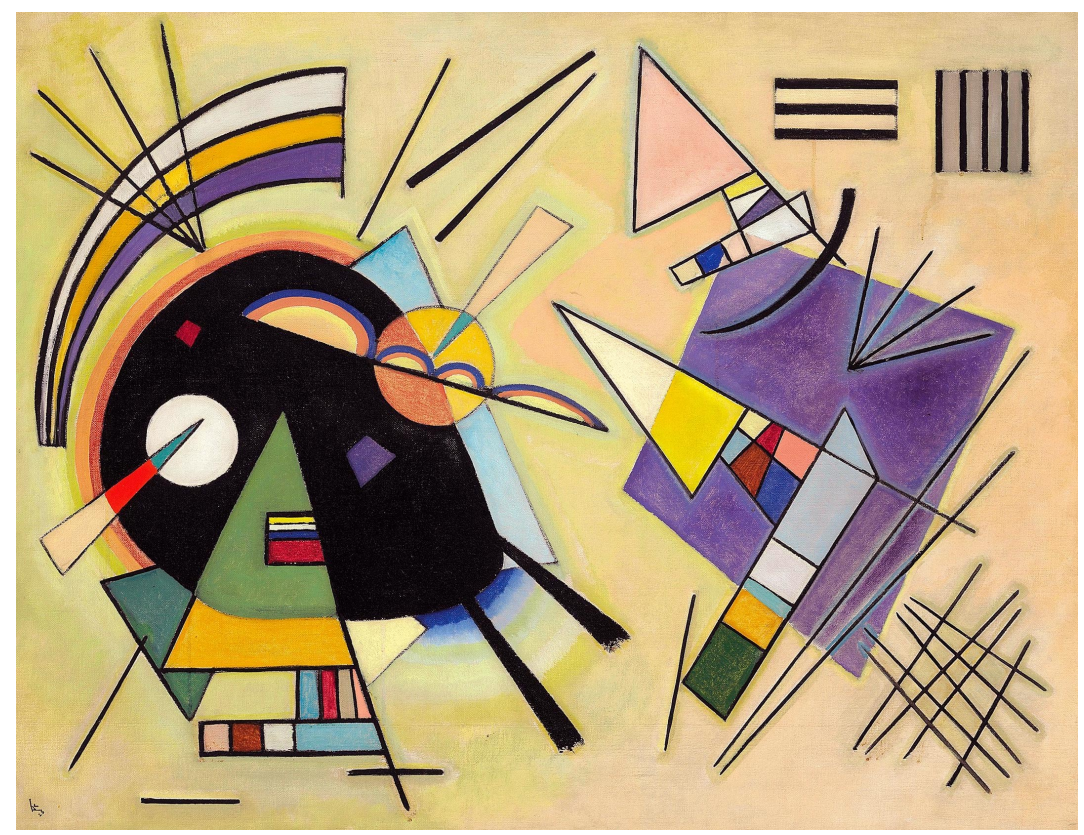

Figure 41. Wassily Kandinsky, Black and Violet, Oil on Canvas, 30.6x39.5 inches, 1923. 


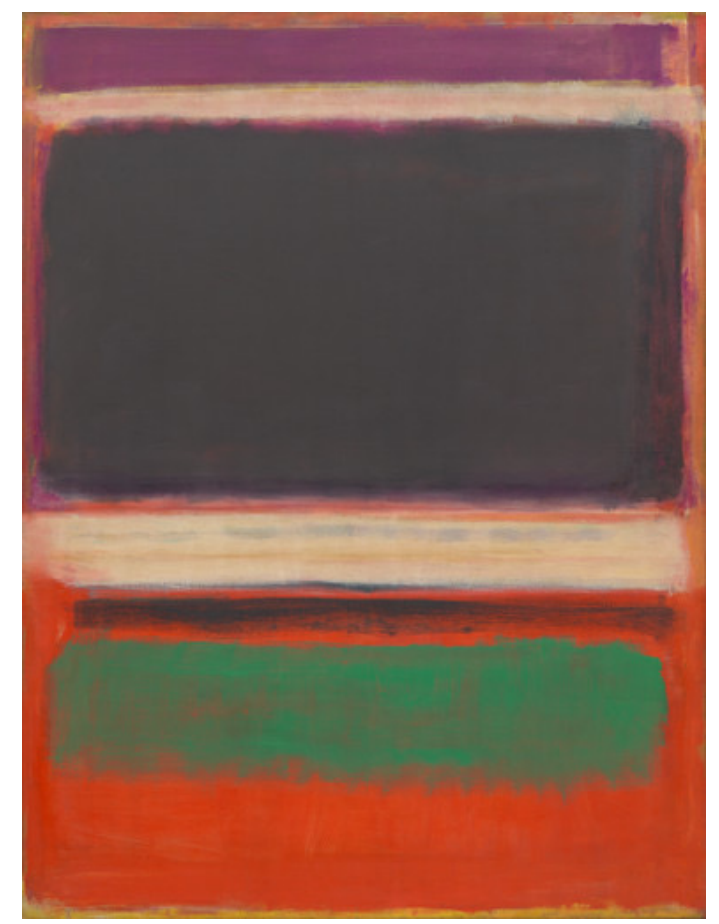

Figure 42. Mark Rothko, No. 3/No.13, Oil on Canvas, 85.2x64.8 inches, 1949.

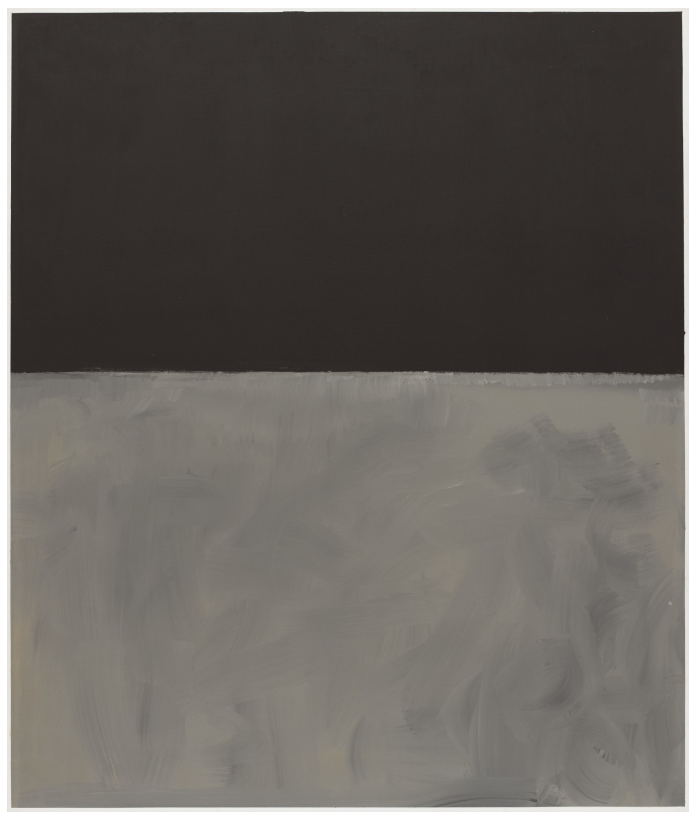

Figure 43. Mark Rothko, Untitled, Synthetic Polymer Paint on Canvas, 77.9x66 inches, 19691970. 


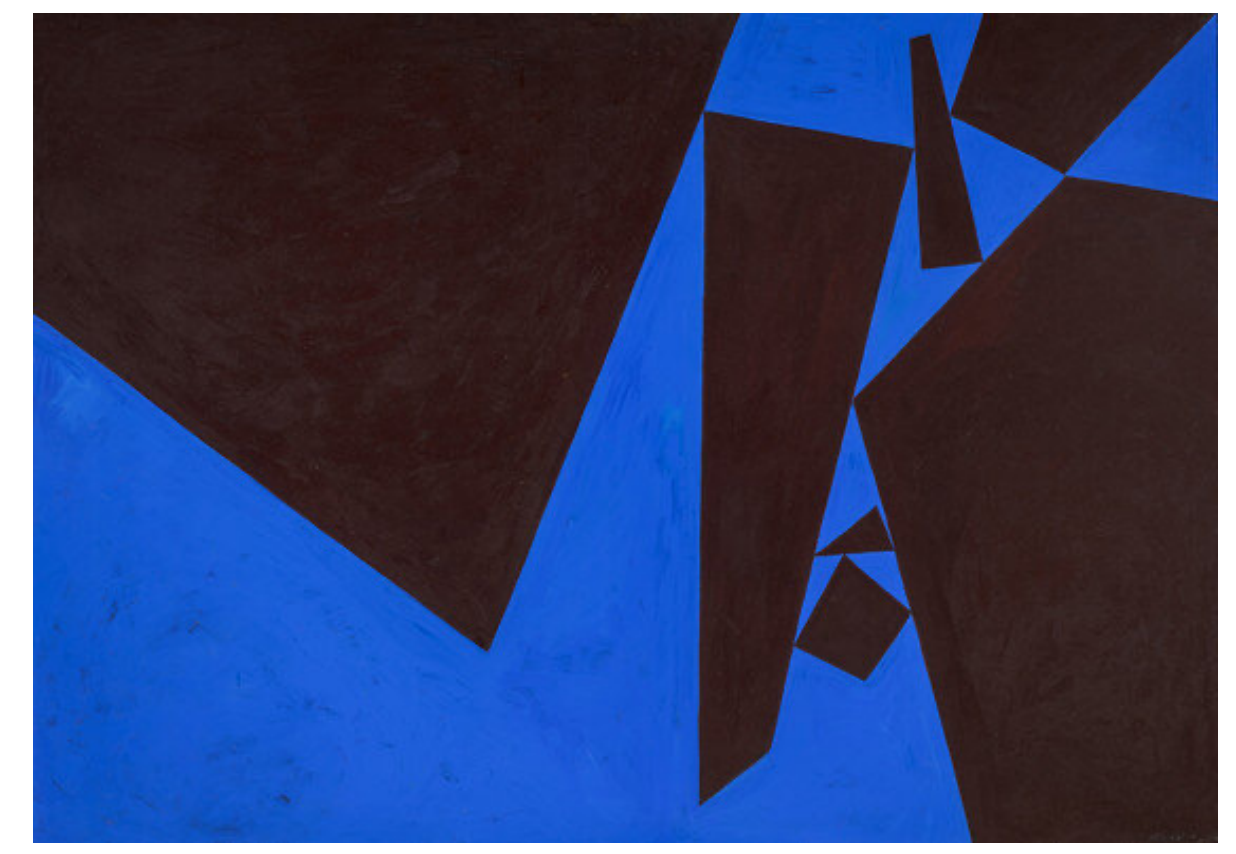

Figure 44. Lorser Feitelson, Geomorphic Metaphor, Oil on Canvas, 58x82 inches, 1950-51. 


\section{Bibliography}

Albano, C. (2012). Fear and Art in the Contemporary World. London: Reaktion.

Babbitt, E. (1878). The Principles of Light and Color. New York: Babbitt \& Co.

Batchelor, D. (2000). Chromophobia. London, England: Reaktion.

Birren, F. (2013). Color Psychology and Color Therapy: A Factual Study of the Influence of Color on Human Life. Mansfield Centre, CT: Martino Publishing.

Croock, S. Stefaan de Croock Transforms Discarded Wooden Doors and Panels Into Giant Murals. Goldie. Accessed 01/05/2020. http://thisisgoldie.squarespace.com/stefande-crook.

Feitelson, L. Artworks, Biography, Books, Quotes, \& Articles. Accessed 01/05/2020. https://www.lorserfeitelson.com/new-page.

Grovier, K. (2015). Art Since 1989. London: Thames \& Hudson.

Harrison, C., \& Wood, P. (2003). Art in Theory 1900-2000: An Anthology of Changing Ideas. Oxford: Blackwell Publishing.

Kandel, E. R. (2018). Reductionism in Art and Brain Science: Bridging the Two Cultures. New York: Columbia University Press.

Kocur, Z, \& Leung, S. (2013). Theory in Contemporary Art Since 1985. Chichester, West Sussex: Wiley Blackwell.

Kandinsky, W. Artworks, Biography, Books, Quotes, \& Articles. Accessed 12/10/2019. https://www.wassilykandinsky.net/work-50.php.

Noorata, P. (2015). Artist Uses Discarded Doors to Create Giant Street Murals. My Modern Met. Accessed 03/15/2020.

Malchiodi, C. (2007). The Art Therapy Sourcebook. New York: McGraw-Hill. 
Popova, M. Kandinsky on the Spiritual Element in Art and the Three Responsibilities of Artists. Accessed 12/10/2019. https://www.brainpickings.org/2014/06/02kandinskyconcerning-the-spiritual-in art/. https://mymodernmet.com/strook-elsewhere-woodand-paint/.

Rogers, N. (1993). The Creative Connection. Science \& Behavior Books, Inc.

Rothko, M. MoMa. Accessed 01/05/2020. https://www.moma.org/collection/works/7968? artist ${ }_{-}$d $=5047 \&$ locale $=$ en\&page $=1 \&$ sovreferrer $=$ artist.

Rose, G. (1991). Abstract Art and Emotion: Expressive Form and the Sense of Wholeness. Journal of the American Psychoanalytic Association, 39(1), 131-156.

Rubin, J. (2010). Introduction to Art Therapy. Taylor and Francis Group, LLC.

Schroder, D. (2005). Little Windows into Art Therapy. Jessica Kingsley Publishers.

Ulanov, A. (2013) Madness \& Creativity. Texas A\&M University Press. 


\section{Olivia Lauren Oddo}

102 Park East Road, Prosperity PA, 15329

livoddo23@gmail.com

(724) $344-1875$

\section{Education}

2020

MFA Candidate in Painting, West Virginia University, Morgantown WV

2016

BA in Studio Art, Concentration in Graphic Design Washington \& Jefferson College, Washington PA

2015

Berlin, Germany Study, Washington \& Jefferson College, Washington PA Studied the language as well as the Bauhaus, Berlin MoMa, Sachsenhausen, etc.

\section{Professional Experience}

2016

Wooden Tooth Literary Journal, Washington \& Jefferson College, Washington PA Artwork published on the cover.

German Day Representative, Washington \& Jefferson College, Washington PA Spoke German and assisted in activities with all if the visiting Washington County schools.

2015 - 16 Olin Fine Arts Center Stage Crew, Washington \& Jefferson College, Washington PA

Olin Fine Arts Gallery Supervisor, Washington \& Jefferson College, Washington PA

Responsible for gallery workers schedules, assisting visiting artists, and reviewing visiting artist applications.

2012 - 16 Olin Fine Arts Gallery Attendant, Washing \& Jefferson College, Washington PA

Responsible for overseeing the displayed artwork, repairing the gallery, and assisting visitors.

2015 Alumni House Greeting Card Designer, Washington \& Jefferson College, Washington PA

Commissioned to create the college's Christmas card.

Admission House Portrait Painter, Washington \& Jefferson College, Washington PA

Commissioned by the president of the college to paint a portrait of George Washington and Thomas Jefferson.

Presidential Showcase Art Department Representative, Washington \& Jefferson College, Washington PA Represented the art department during visiting student tours. 
Awards

2020 The Honor Society of Phi Kappa Phi

West Virginia University, Morgantown WV

The National Society of Leadership and Success

West Virginia University, Morgantown WV

Mesaros Foundation Graduate Thesis Research Award

West Virginia University, Morgantown WV

2017-20 Graduate Waiver Hours

West Virginia University, Morgantown WV

2016

Art Department Proficiency Award \& Book Dedication, Washington \& Jefferson College, Washington PA

2012-16 Academic Dean's Award

Washington \& Jefferson College, Washington PA

\section{Exhibitions}

2020

[SOLO] Disquiet Depictions, Laura Mesaros Gallery, West Virginia University, Morgantown WV.

2017 [GROUP] Confluence, Artists Image Resource, Pittsburgh PA

[SOLO] Pop Portraits, Patty's Art Spot, Morgantown WV

2016

[GROUP] Limelight, Olin Fine Arts Center, Washington \& Jefferson College, Washington PA 